\title{
Antiviral drug research for Japanese encephalitis: an updated review
}

\author{
Shaun Joe ${ }^{1}$ Abdul Ajees Abdul Salam ${ }^{2} \cdot$ Ujjwal Neogi $^{1,3} \cdot$ Naren Babu N $^{1} \cdot$ Piya Paul Mudgal ${ }^{1}[$
}

Received: 18 November 2021 / Revised: 21 January 2022 / Accepted: 28 January 2022 / Published online: 19 February 2022

(c) The Author(s) 2022

\begin{abstract}
Japanese encephalitis (JE) caused by the Japanese encephalitis virus (JEV) is one of Asia's most common viral encephalitis. $\mathrm{JEV}$ is a flavivirus, common in rural and sub-urban regions of Asian countries. Although only $1 \%$ of JEV-infected individuals develop JE, there is a 20-30\% chance of death among these individuals and possible neurological sequelae post-infection. No licensed anti-JE drugs are currently available, despite extensive efforts to develop them. Literature search was performed using databases such as PubMed Central, Google Scholar, Wiley Online Library, etc. using keywords such as Japanese encephalitis virus, antiviral drugs, antiviral drug screening, antiviral drug targets, etc. From around 230 papers/abstracts and research reviews retrieved and reviewed for this study, approximately 180 most relevant and important ones have been cited. Different approaches in drug testing and various antiviral drug targets explored so far have been thoroughly searched from the literature and compiled, besides addressing the future perspectives of the antiviral drug development strategies. Although the development of effective anti-JE drugs is an urgent issue, only supportive care is currently available. Recent advancements in understanding the biology of infection and new drug targets have been promising improvements. Despite hindrances such as the unavailability of a proper drug delivery system or a treatment regimen irrespective of the stage of infection, several promising anti-JE candidate molecules are in different phases of clinical trials. Nonetheless, efficient therapy against JEV is expected to be achieved with drug combinations and a highly targeted drug delivery system soon.
\end{abstract}

\section{Graphical abstract}

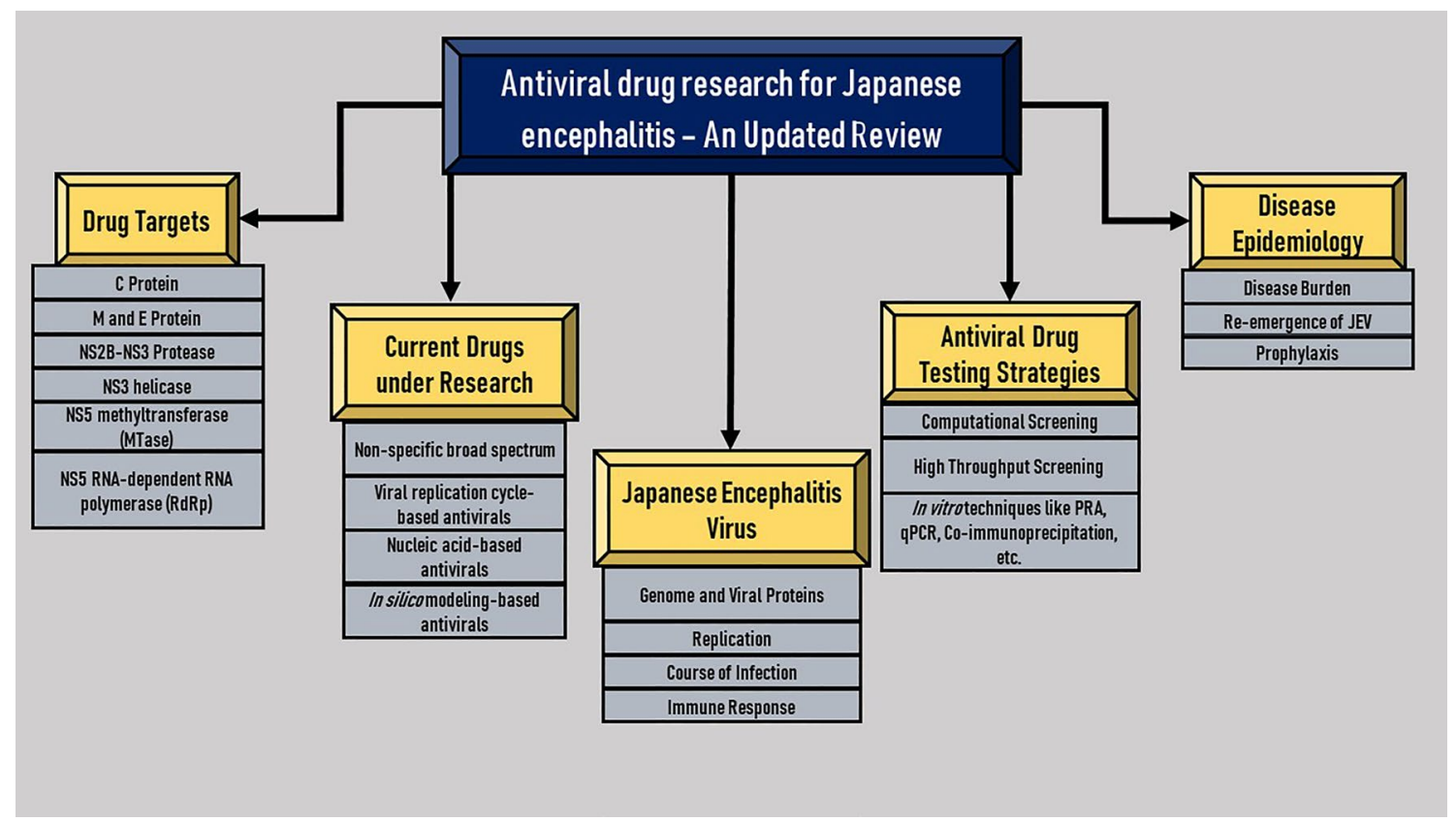

Extended author information available on the last page of the article 
Keywords Antiviral · Drug targets $\cdot$ In-silico molecular modeling $\cdot$ Japanese encephalitis virus $\cdot$ Nucleic acid-based antiviral $\cdot$ Replication cycle-based antiviral Screening

\begin{tabular}{ll}
\multicolumn{2}{l}{ Abbreviations } \\
Asn & Asparagine \\
Asp & Aspartic acid \\
C & Capsid \\
Cys & Cysteine \\
DNA & Deoxyribonucleic acid \\
DNAzymes & Deoxyribozymes \\
E & Envelope \\
eIF2a & Eukaryotic initiation factor 2a \\
ERK & Extracellular-signal-regulated kinases \\
fsRNA & Frameshift site RNA \\
Gly & Glycine \\
Glu & Glutamic acid \\
HSP70 & Heat Shock Proteins 70 \\
His & Histidine \\
IFN- $\gamma$ & Interferon Gamma \\
JEV & Japanese encephalitis virus \\
Lys & Lysine \\
M & Membrane \\
MAPK & Mitogen-activated protein kinases \\
NS & Non-structural \\
NTPase & Nucleoside triphosphatase \\
prM & Premembrane \\
RNA & Ribonucleic acid \\
RdRp & RNA-dependent RNA polymerase \\
Ser & Serine \\
siRNA & Small interfering RNA \\
shRNA & Short hairpin RNA \\
UTR & Untranslated region \\
WHO & World Health Organization \\
\hline &
\end{tabular}

\section{Introduction}

Japanese encephalitis (JE) caused by the Flavivirus, Japanese encephalitis virus (JEV), is the most common viral encephalitis in Asia. Although rare, it has also been reported from northern Australia and western pacific regions [1]. JEV has a single-stranded RNA genome and is primarily transmitted by mosquitoes, Culex vishnuii, and Culex tritaeniorhynchus [2]. Ardeid birds (herons, egrets), along with bats, serve as the primary virus reservoirs. Pigs are the most common amplification hosts for JEV, wherein the virus amplifies, resulting in a very high viral titer. A significant risk factor that facilitates the transmission of JEV to humans is pig rearing. Vector-borne transmission of the virus to humans and domestic animals results in the further spread of JEV. JEV is not transmitted from person to person or from domestic animals such as horses, making humans and horses dead-end hosts [3]. Humans and horses can develop severe symptoms, commonly encephalitis, whereas pigs rarely show any clinical manifestation of the infection. JEV-induced encephalitis has a mortality rate as high as $25-30 \%$, and up to $50 \%$ of surviving patients suffer from neuropsychiatric sequelae [4].

Effective antiviral therapy for JEV is of great importance, owing to the enzootic nature of the virus. This characteristic of the virus enables it to persist in nature to the extent that it is never entirely eradicated from the environment [5]. With the advent of modern technologies, research in antiviral drug development for JE has seen a sturdy increase in the last few decades. Making a therapeutic drug readily available to the JEV risk groups at an affordable cost is the primary aim of the JEV antiviral research [5, 6].

This review discusses the current strategies and approaches in antiviral drug research against JEV and the recent trends in discovering virus-targeted compounds that can be potentially developed into therapeutic drugs.

\section{JEV genome and structure}

JEV comprises a single-stranded, positive-sense RNA genome, $\sim 11 \mathrm{~kb}$ in length. The genome has one openreading frame (ORF) encoded between the $5^{\prime}$ and $3^{\prime}$ noncoding regions (NCRs) and lacks a poly-A tail at the $3^{\prime}$ end. The open-reading frame codes for a polyprotein precursor ( 3432 amino acids), which gives rise to ten distinct proteins, comprising of the three structural (capsid, C; premembrane, $\mathrm{M}$; and envelope, $\mathrm{E}$ ) and the seven non-structural (NS1, NS2A, NS2B, NS3, NS4A, NS4B, and NS5) proteins $[7,8]$ (Fig. 1A). There are primarily four proteases involved in the site-specific cleavage of the polyprotein to yield the functional proteins (Table 1).

\section{Structural proteins}

JEV is roughly spherical with a diameter of $510 \AA$. It is composed of three structural proteins and an outer lipid bilayer membrane. The $\mathrm{E}$ and $\mathrm{M}$ proteins protrude from the lipid membrane and are anchored through transmembrane helices. The viral capsid is disordered and encloses the viral genome (Fig. 1B). It plays a pivotal role in viral replication and nucleocapsid formation. The precursor M protein (prM) is involved in folding the $\mathrm{E}$ protein. It acts as a chaperon and prevents the oligomeric rearrangement of $\mathrm{E}$ proteins triggered by the low $\mathrm{pH}$ of the endosome. The $\mathrm{E}$ protein activates membrane fusion by binding to the virus-specific cellular receptor and highly immunogenic protein. It is also 
A

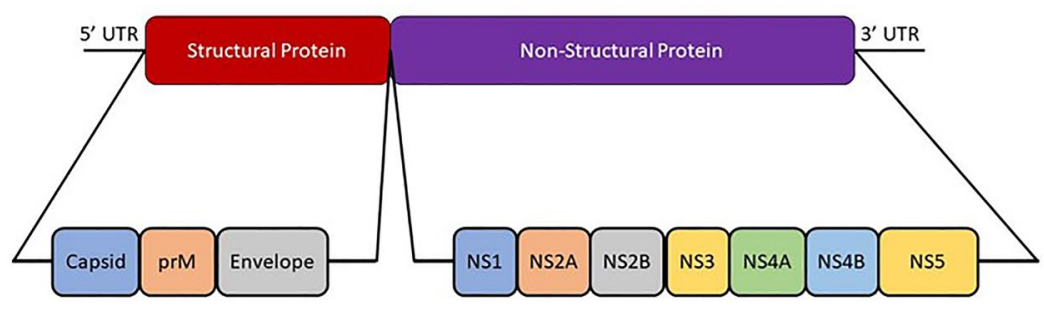

B

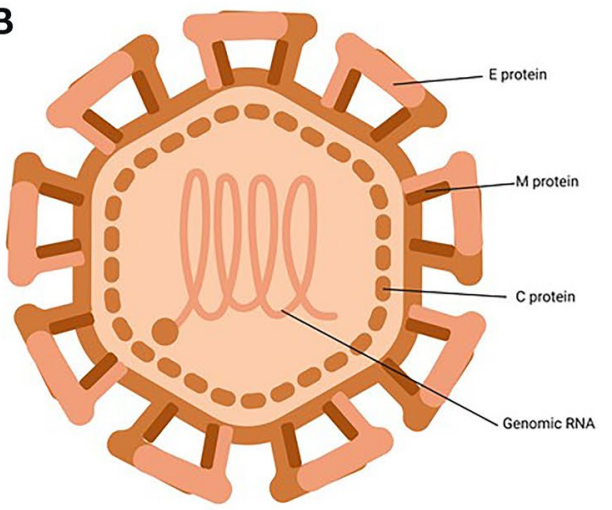

Fig. 1 A Japanese encephalitis virus genome; $\mathbf{B}$ structure of Japanese encephalitis virus

Table 1 Proteases involved in viral replication

\begin{tabular}{lll}
\hline Protease & Origin & Function \\
\hline Signal peptidase & Host protease & $\begin{array}{c}\text { Cleaves at the C-M, M-E, E-NS1, and } \\
\text { NS4A-NS4B junctions [7-9] } \\
\text { Protease NS3-NS2B }\end{array}$ \\
& Viral protease & Cleaves at the NS2A-NS2B, NS2B-NS3, \\
& NS3-NS4A, and NS4B-NS5 junctions \\
& Internal sites within the C and NS4A pro- \\
& teins [7-9] \\
Furin-like protease & Cleaves precursor M (prM) to M [7-9] \\
Protease enzyme & Host protease & Cleaves at the NS1-NS2A junction [7-9] \\
\hline
\end{tabular}

$C$ capsid, $M$ membrane, $E$ envelope, $N S$ non-structural, $p r M$ premembrane essential for the entry of the virion into the cells, protein assembly, and budding [8-11].

\section{Non-structural proteins}

The exact function of NS1 protein remains unclear, although it is understood to be involved in the replication step as it localizes with the double-stranded RNA (dsRNA) [12]. The flavivirus NS2A protein is essential for genome synthesis and assembly. The NS2B protein complex with the NS3 protein exhibits serine protease activity at the $\mathrm{N}$-terminal $[10,13]$. The C-terminal region of NS3 protein has helicase activity $[8,10]$.

NS5, just like NS3, is a multi-enzymatic protein with a guanylyltransferase/methyltransferase domain in the N-terminal region and an RNA-dependent RNA polymerase domain in the C-terminal. The interaction of NS3 and NS5 is of utmost importance during the replication cycle. The hydrophobic NS4A coordinates with NS1 during replication; however, the function served by this alignment is unclear. Similarly, the role of flavivirus NS4B protein is hardly known, although NS4B has been also found to co-localize with dsRNA. Guanylyltransferase/methyltransferase domain of the NS5 protein is responsible for the $5^{\prime}$ capping of the genomic RNA, and the RNA-dependent RNA polymerase domain mediates RNA replication [8, 10, 13-15].

Replication JEV is a flavivirus in which the nucleocapsid is enclosed by a lipid bilayer composed of the membraneanchored $\mathrm{M}$ and $\mathrm{E}$ proteins. JEV, along with the other flaviviruses, shares a similar replication mechanism. Viral entry is an active process involving several complex interactions between the virus and the host cell. These non-specific binding of the E protein to cellular receptors like heparin sulfate, on the cell surface, further facilitates more specific interactions [13] (Fig. 2A). Cellular receptors like PLVAP (plasmalemma vesicle-associated protein) and GKN3 (gastrokine3) promote clathrin-dependent or clathrin-independent endosome formation $[8,14]$. The low $\mathrm{pH}$ inside the endosome induces conformational changes in the $\mathrm{E}$ protein, triggering the fusion of the viral membrane with the inner wall of the endosomal membrane. The genome is released into the cytoplasm immediately after the fusion of the membranes and is translated into the precursor polyproteins [8, 13, 14].

In the cytoplasm, the precursor polyproteins are translated from the genome and are cleaved into two precursor polyproteins that are further processed to generate the three structural and other non-structural proteins $[7,8,11]$. The non-structural proteins, along with host factors, are involved 


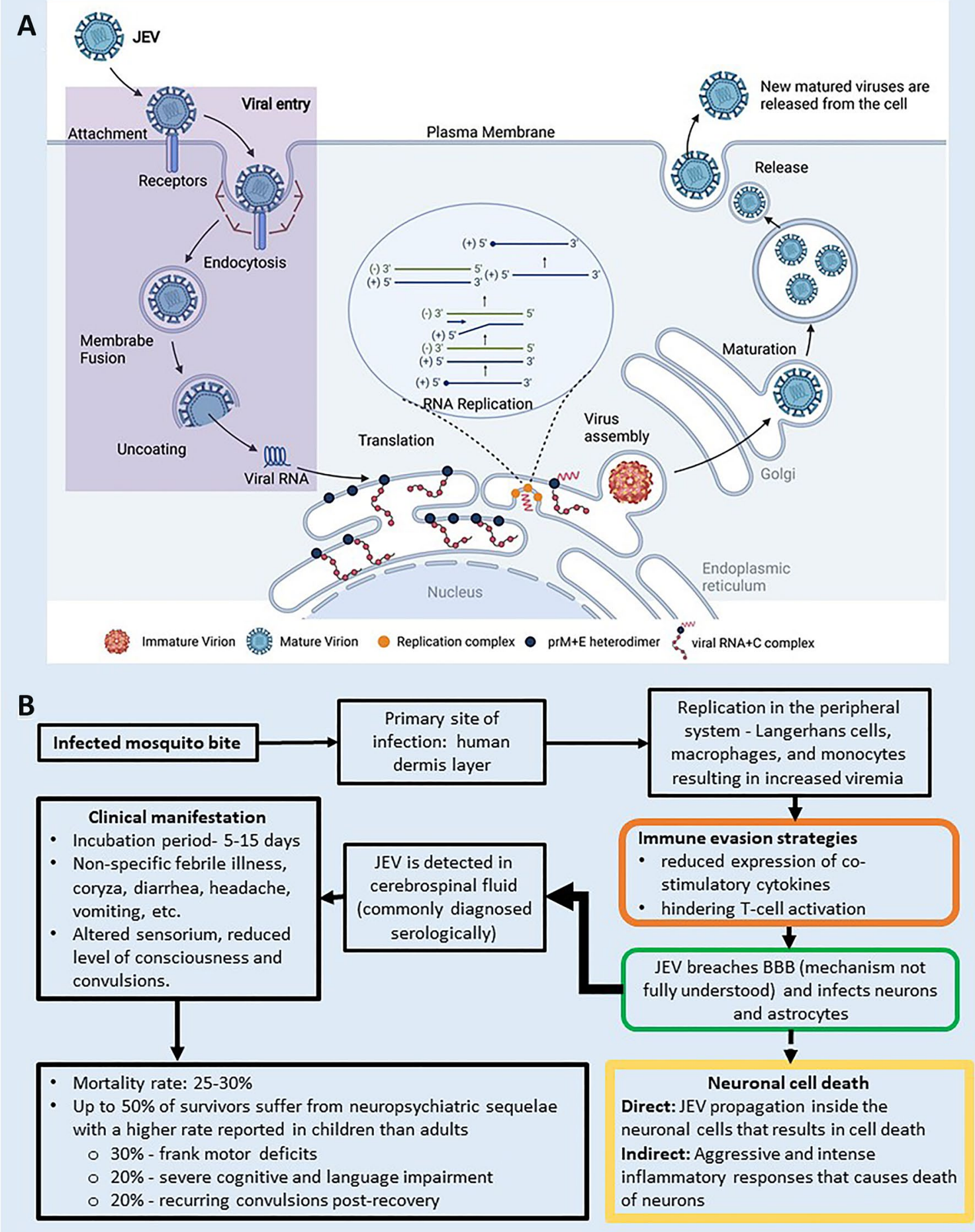

Fig. 2 A Japanese encephalitis virus replication [16, 17]; B the progress of Japanese encephalitis virus infection

in the viral replication that occurs in the viroplasm. Viroplasm is an ER-derived membranous organelle housing the replication complexes and is the site of viral RNA synthesis. NS3 and NS5 catalyze the replication step and coordinate their multiple enzymatic activities to facilitate RNA synthesis, 5 ' capping, and methylation $[8,11,18]$. The $\mathrm{C}$ protein complexed with the newly synthesized genomic RNA is enveloped on the ER membrane with two viral glycoproteins (prM and E). This step results in the formation of the immature virion composed of 60 protruding spikes 
made of prM and $\mathrm{E}$ heterodimers. The constitutive secretory pathway followed by furin-mediated cleavage of the prM protein to $\mathrm{M}$ in the trans-Golgi network results in viral maturation. The mature virions ( $\sim 50 \mathrm{~nm}$ diameter), composed of 30 densely packed rafts of hetero-tetramers made of $\mathrm{E}$ and $\mathrm{M}$ proteins, are released by budding [13]. The progress of infection and its development to Japanese encephalitis is illustrated in Fig. 2B [19-22].

\section{Disease burden}

\section{Global outlook}

From as early as the 1870 s, frequent outbreaks of encephalitis have been reported from Japan. Significant epidemics were recorded every 10 years, with occasional peaks of encephalitis cases occurring during the summer season. These cases of encephalitis were then called 'type B encephalitis' to distinguish it from von Economo's encephalitis clearly. In 1935, the Nakayama strain of JEV was first isolated from an infected patient, and the virus was named 'Japanese encephalitis virus'. The virus was then classified into the genus Flavivirus (family-Flaviviridae) [6]. Flaviviruses comprise over 70 different virus species, and phylogenetic analysis suggests that JEV evolved from an African ancestral virus. The present circulating strain of JEV was traced to have evolved from the ancestral strain in the Indonesian-Malaysian region. The virus was then distributed across Southern and eastern parts of Asia and Pacific regions over time [23]. Rapid urbanization, population explosion, climate change, globalization, and deforestation have resulted in the spread of the virus from one area to the other [6]. Today, up to $60 \%$ of the world's population is inhabiting JE-endemic region. Approximately 67,900 cases of JE occur annually, of which only $10 \%$ of cases are reported to the World Health Organization [1]. Around 50\% of these cases occur in China, and approximately $75 \%$ affected are children aged 0-14. These are some of the aspects, which make JE one of the most significant viral encephalitis globally [1]. The WHO published the number of JEV cases reported from different countries around the world. These data were published in 2020 and were focused on vaccine-preventable diseases and immunization monitoring [24]. The countries which recorded the maximum number of JE cases over the years are discussed below.

\section{Distribution around the world}

China Chinese mainland records a high prevalence of JEV and is the foremost region of JEV endemism. China has an efficient and sensitive system to trace each JE case annually. This case reporting system was established in 1951, and has been an integral part of managing and mitigating various spikes and outbreaks of JEV. Although cases are reported throughout the year, they significantly rise from June to October. The number of morbidities from these months' accounts for $97 \%$ of the overall cases in mainland China. Two major JE epidemics have been reported in China1966 and 1971 [25-27]. The overall trend in the number of JEV cases in China from 2009 to 2019 is represented in Fig. 3A [24].

India India's first case of JEV was recorded in 1955 and was first isolated in 1958. Until the early 1970s, JE was reported only from southern India but received nationwide attention after the significant outbreak in 1973 from the Bankura district of West Bengal with a $42.6 \%$ case-fatality rate. Subsequently, several cases of encephalitis were reported from different parts of the country [28]. India's biggest outbreak of Japanese encephalitis in recent history occurred in 2005 in northern India. The outbreak started with several cases reported from the state of Uttar Pradesh in July 2005, which escalated to nearly 5000 cases, mounting up to 1300 deaths by November 2005 [29]. Presently, there are 1000-2500 cases reported annually from India. These numbers are based on the total cases reported around the country, as collated in the National Vector Borne Disease Control and Prevention (NVBDCP) database. The actual disease burden of JE is expected to be higher in both the Indian as well as global context due to the several unreported cases [30]. India has seen a stable increase in JE cases over the years, as depicted in Fig. 3A [24].

Myanmar Myanmar (formerly Burma) is a South Asian country endemic to JEV. A significant surge in the number of JE cases was first recorded in the Shan State, Myanmar, in 1974. The WHO has recorded an average of 118 cases per year. 2016 saw an increase in JE cases, which peaked by August 2017 in Myanmar. A steady decline was observed in the JE cases in Myanmar after 2017 due to several interventions such as control measures, vaccination programs, appropriate preparedness, and response (Fig. 3A) [24, 31].

Nepal Nepal is a landlocked country sharing its borders with China and India. JE was first confirmed in the year 1978 and has been recorded steadily since. The surveillance of JE cases in Nepal is being monitored since 2004 by the World Health Organization (WHO) through a network of national vaccine-preventable diseases [32]. An average of 235 cases is recorded every year with a spike observed in 2014 (Fig. 3A) [24].

Vietnam First isolated as early as 1951, JE is one of Vietnam's chief public health problems. Due to insufficient laboratory testing capabilities, acute encephalitis, an essential manifestation of JE, is considered a marker and reported for 


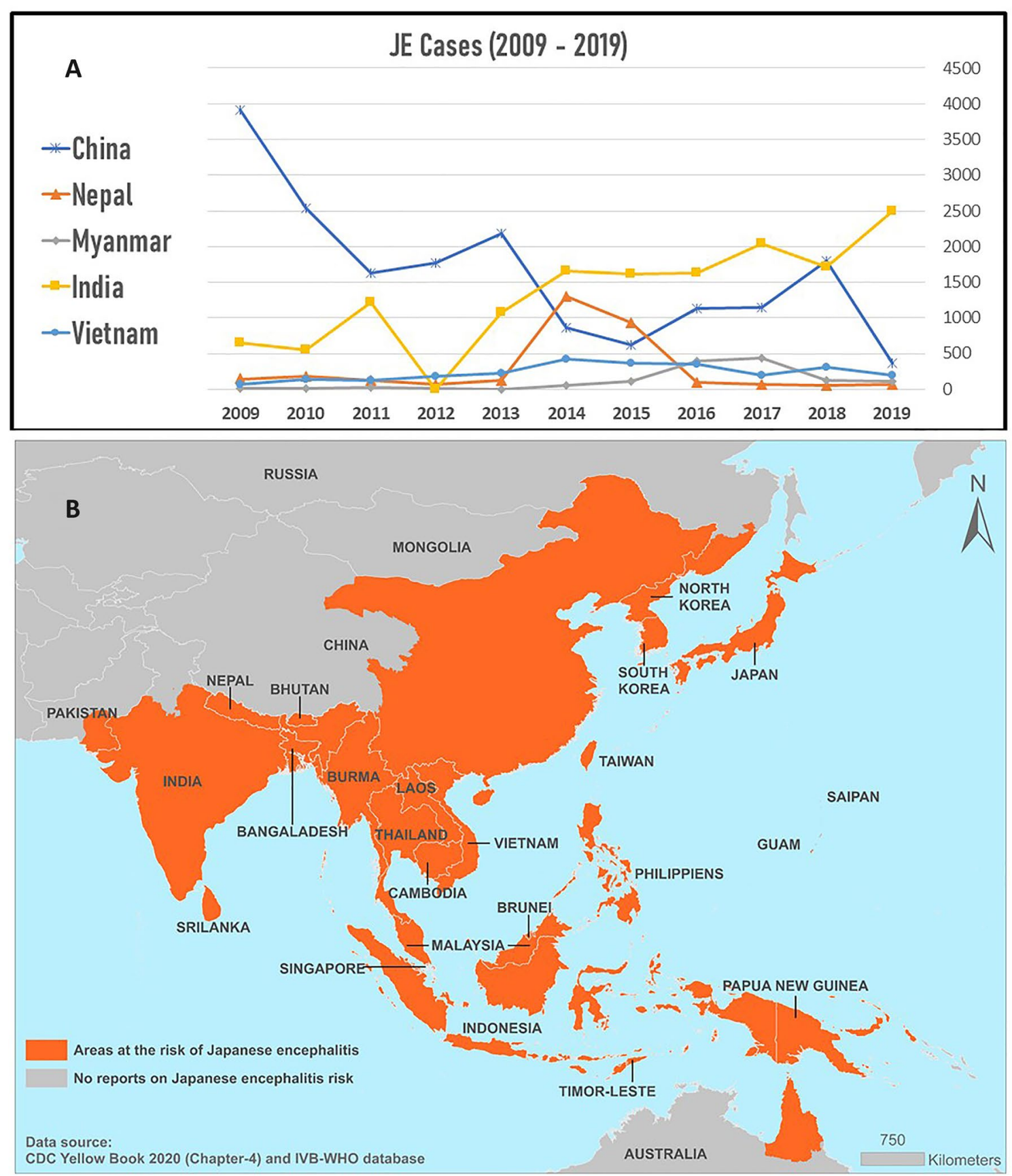

Fig. 3 A JE cases from 2009 to 2019 in China, Nepal, Myanmar, India, and Vietnam. These countries are endemic to JEV and contribute towards a majority of the overall cases reported around the world;

JE surveillance. Over recent years, an average of 236 cases per year has been recorded, with a significant increase in 2014-2016 (Fig. 3A). Substantial measures like nationwide vaccination programs, vector control, etc. have successfully brought down the number of cases [24, 33].
B geographic distribution of Japanese encephalitis virus (JEV). The JEV distribution map was created using ArcGIS v.10.4 (ESRI, Redlands, CA, USA)

\section{Epidemiology}

The fatality of JE is as high as $20-30 \%$, and a staggering $30-50 \%$ of survivors develop substantial neurologic sequelae. JE primarily affects children, but all age groups may be affected. Post-infection, most individuals develop natural immunity [1]. Two distinctive patterns of JEV cases have been observed from the tropical and temperate regions of 
JE-endemic countries. Significantly, large epidemics occur during the summer season in temperate areas like Nepal, China, Japan, the Korean peninsula, and northern India. On the contrary, although case distribution is sporadic during the rainy season, the cases peaks in the tropical regions, particularly the southern part of Vietnam, Thailand, Indonesia, and Sri Lanka [7, 34].

There are five different genotypes of JEV (namely I, II, III, IV, and V) based on the gene sequence of the E protein [35]. The difference in the virulence of each genotype in humans is debated. Genotype III has a more widespread geographical distribution than the other four genotypes. A motley collection of ecological, environmental, climatic, and human behavioral factors like irrigation schemes, development of the rice industry, etc., have resulted in the virus spread [29]. Figure 3B summarizes the geographic distribution of JEV.

\section{Re-emergence of JEV}

There are primarily two factors that account for the re-emergence of JEV. First, there has been an unprecedented and rapid surge in the population of the JE-endemic countries in the past decades. One such example of the population increase was observed in the endemic Asian regions. The population of around 1.7 billion in the mid-twentieth century almost doubled to around 3.5 billion by the early 2000s. Second, the escalation of pig rearing for food, coupled with the development of rice-production systems, which fueled rice farming and cropping intensity, also contributed to the emergence of JEV. An example to quote in this context would be an increase in pork production in China, which doubled from 1990 to 2005 [29, 34].

\section{Prophylaxis}

Prophylaxis is the best way to prevent JEV infection. The control of Culex mosquitoes, the primary vectors for JEV, is crucial for prevention. Figure 4 shows the life cycle of JEV. Ideal breeding grounds for mosquitoes, such as paddy fields, help spread the virus by attracting migratory birds. Control measures in paddy fields may include the use of larvicides and larvivores such as guppy fishes (Poecilia reticulata) [6]. Close monitoring of animals is vital in pig rearing to prevent pigs' infection. Vaccination of these animals is also a logical way to break the transmission of JEV to pigs [36, 37].

\section{Limitations of prophylaxis}

The most effective method to prevent JE would be the selective vaccination of risk groups. The discovery of the live attenuated vaccine for JEV has proved efficient in preventing

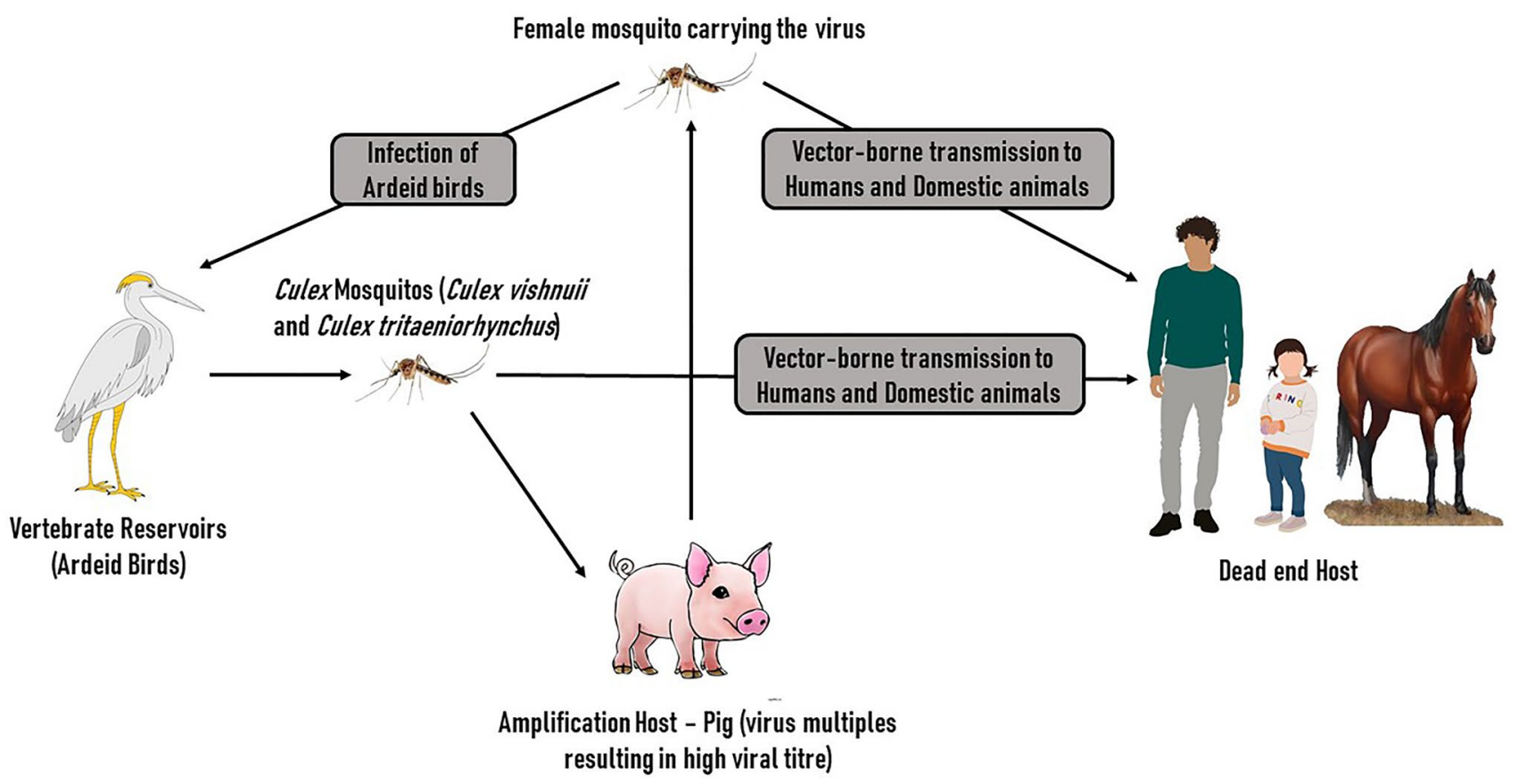

Fig. 4 The life cycle of Japanese Encephalitis Virus. Ardeid birds (pond herons, egrets) serve as virus reservoirs causing the enzootic nature of the virus. Culex mosquitoes that feed on a viraemic host get infected, and actively transmit the virus to other hosts after 9-12 days of incubation. Pigs often act as amplification hosts and do not manifest any significant symptoms of the infection. They are the primary host of the virus. The vector-borne transmission of the virus to man and domestic animals leads to a severe disease condition. The absence of person-to-person transmission makes man a "dead-end" host 
JE [38]. Although the vaccine requires multiple doses, it is relatively safe and effective [6]. There has been no other variable that significantly reduced the JE disease burden, and therefore, prompt immunization is prioritized over mosquito control and life stock management. Vaccination is highly recommended in places suitable for JEV transmission even if the reported JE cases are fewer. WHO recommends that all travelers to JEV endemic regions take precautions and get vaccinated to reduce the risk for JE [10].

Currently, various inactivated vaccines (mouse brainderived, Vero cell-derived) and live vaccines (attenuated and recombinant (chimeric)) are in use. Among vaccine candidates in the late clinical trial phases, a live attenuated, yellow fever virus-based chimeric vaccine developed in Vero cells is the most promising candidate. A single dose has shown to be highly productive. Live attenuated vaccine made from the SA14-14-2 virus strain is the most widely used vaccine in JE-endemic areas and has $99.3 \%$ efficacy. The single dose of the vaccine was most efficacious when administered days/ weeks before possible exposure to infection $[7,8,10]$.

The most challenging task is rendering the vaccine available to the poor and rural communities, considering the compliance and delivery costs. Imprecise estimation of JEV disease burden in certain areas due to the absence of efficient surveillance infrastructure reduces the vaccine's reach. Public health interventions often focus on control measures over JEV immunization due to the vaccine's enormous cost and multiple-dose regimen $[8,10]$. All these evidence points towards the significance of developing an efficient antiviral drug for JE treatment.

\section{Current therapeutic strategies}

Current treatment strategies for JEV infection mainly involve supportive care and are not targeted at attenuating the virus [6]. A study investigating the use of ribavirin (a broadspectrum antiviral) against JEV by controlled clinical trials showed that ribavirin has a more negligible effect on treating JEV [39]. A naturally occurring compound called 'rosmarinic acid', found in various Labiatae herbs, reported to have antiviral activity against Flaviviruses, was used for preclinical studies. This compound reduced viral replication of JEV (GP78 strain) in mice brains [40]. Curcumin is another compound shown to have antiviral activity against JEV in an in-vitro study. This compound reduced cellular reactive oxygen species level and maintained cell membrane integrity, thus preventing cell death. It was also observed that curcumin reduced apoptotic signaling molecules and stress-related proteins [41]. Minocycline, a derivative of the tetracycline group of antibiotics, showed remarkable results as an antiviral drug for JEV. An in-vivo study exploring its potential as a possible anti-JEV drug also showed promising results. Minocycline reduced viral titer significantly and prevented neuronal apoptosis and microglial activation [42]. The blood-brain barrier, which becomes impaired during the infection, was protected due to minocycline effects [43].

The budding of dengue type II (DEN-2) and JEV through the endoplasmic reticulum can be hindered by glucosidase inhibitors like $\mathrm{N}$-nonyl-deoxynojirimycin ( $N \mathrm{~N}-\mathrm{DNJ}$ ). $N \mathrm{~N}-\mathrm{DNJ}$ is an imino sugar derivative that interrupts virus development by blocking the trimming step of N-linked glycosylation, thus causing misfolding of viral protein [44]. Another novel approach targeted the 3 ' non-coding region of JEV using a synthetic oligonucleotide-based DNAzyme, which successfully inhibited virus replication in-vitro as well as in a mouse model [45].

Several approved antivirals have been repurposed to check for activity against JEV. These studies were focused on specific drug targets and were studied by high-throughput screening, computational methods, etc. Calcium inhibitors such as manidipine, cilnidipine, and benidipine hydrochloride inhibited virus infection at either entry or replication and even during budding [46]. Although these compounds were promising and had high efficacy in in-vitro or in-vivo systems, they failed to reproduce similar effectiveness in human trials or were found unsuitable for use in a clinical study. A placebo-controlled clinical trial with interferonalpha-2a, in confirmed JE cases in children, remains the only study to date effective against JEV. Unfortunately, after 3 months of their discharge, a survey proved the inefficiency of interferon-alpha-2a in treating JE [47].

\section{Methods}

Research papers, review articles, and books related to JEV and JE, including its transmission and replication cycle, global distribution, disease dynamics, and immune responses, were searched in PubMed Central, Google Scholar, Wiley Online Library, etc. Surveillance data on the recent number of JEV cases in various countries worldwide were retrieved from the WHO and government websites like NVBDCP. Keywords, such as Japanese encephalitis virus, antiviral drugs, antiviral drug screening, etc., were primarily used for the search. Studies published until September 2021 on antiviral drug research against JEV, screening strategies, clinical and laboratory trials, and viral targets were collected for this review. The review focuses on the current disease burden of JEV despite the availability of efficient vaccines, the current research trends, the available viral targets, and the widely studied potential antiviral drugs.

Approximately 230 papers/abstracts and review articles were retrieved and reviewed for this work. Various drugs studied for their potential anti-JEV activity were screened and collected to form a database. The drugs were sorted into three categories within the database after considering 
their targets, specificity, mode of action, etc. The various strategies employed to examine the antiviral activity of these drugs were also compiled. The different viral proteins and the potential therapeutic targets were also explored. The developments in recent years in understanding the biology of infection and the molecular mechanisms of viral replication were also discussed. This article is based on previously conducted studies and does not contain any new studies with human participants or animals performed by any authors.

\section{Viral targets and the course of infection}

\section{Pathogenesis}

The incubation period of JEV ranges between 5 and 15 days. The number of factors, such as route of entry, the virulence of the virus, genetic make-up, age of the host, etc., determine whether the infection progresses to JE [29]. The first step after the bite of an infected mosquito is the local replication of the virus in the skin, followed by transportation of the virus to the regional lymph nodes. The virus amplifies in the peripheral system (Langerhans cells, macrophages, and monocytes), resulting in high viremia, followed by the central nervous system (CNS). The virus is embedded in the connective tissue and other tissue during this amplification period. The clinical symptoms are entirely dependent on the invasion of the CNS from the blood [20, 21, 28].

If the virus can access susceptible neural cells of the CNS, it can lead to encephalitis. However, the infection of the nonneural tissues results in asymptomatic cases. Therefore, it is crucial to understand the mechanism of virus penetration to the CNS in comprehending the pathogenesis of viral diseases [48]. Although the process by which JEV crosses the blood-brain barrier is unknown, human post-mortem studies suggest a hematogenous route of entry [49]. Other risk factors, such as dementia, stroke, and sepsis, have been implicated in increasing the chance of neuro-invasion [28].

\section{Immune response}

\section{Innate immune response}

Immediately after the entry of the virus, the host cells interacting with the virus start the production of many cytokines like type- 1 interferons (TNF- $\alpha$ and interferon- $\gamma$ ). These cytokines induce an inflammatory response that inhibits virus replication. In addition to this, IFN- $\alpha$ and $-\beta$ trigger lytic activity in NK cells and kill virally infected cells. IL-2 produced early during the viral infection enhances the lytic activity of NK cells. The activation of macrophages follows this initial activity of NK cells by IFN- $\gamma$, which expresses
MHC class II molecules facilitating microbicidal action [20, $21,43]$.

Granular lymphocytes in the bloodstream further attack the virus-infected cells and destroy them by phagocytosis. These cells are drawn to the entry site by chemoattractant molecules released by the complement system through a multicomponent enzyme cascade [20, 49]. Corticosteroids and anti-inflammatory drugs have been investigated in the treatment of JE [5]. Arctigenin (AR), a naturally occurring plant compound, strongly inhibited TNF-alpha production and reduced the inflammatory responses in an in-vivo study, which established its implications in being used to treat inflammation-related complications [50-52].

\section{Adaptive immune response}

The adaptive immune response is highly specific and can identify diverse pathogens. It displays immunologic memory and recognizes the self from foreign particles. The antigens are recognized by antibodies, after which they are crosschecked with surface receptors of immune cells, and signal molecules are secreted [20, 51, 52]. Lymphocytes and APCs are involved in adaptive immunity. Antigen sensitized B-lymphocytes are converted to effector plasma cells that produce antigen-specific antibodies. They clonally expand and secrete hundreds of antibody molecules that help virus neutralization. They also function as an essential effector molecule of humoral immunity $[49,51,52]$.

JEV has several immune evasion strategies, among which the most important is by continuously altering their antigenic epitopes to transform themselves into new locally adapted quasispecies [53]. These new strains are often more virulent and are capable of causing severe infection. Thus, through significant mutations, the virus modifies itself and proceeds to be neurovirulent as they migrate to the CNS. The absence of protective immunity against newly emerged strains can result in the development of viral encephalitis. Thus, the humoral immune response plays a crucial role in protecting against JEV[20, 51, 53, 54].

\section{Cell-mediated immune response}

Along with the humoral immune response, cell-mediated immunity plays a vital role in clearing up virus-infected cells. It is executed primarily by IFN- $\gamma$-mediated-T helper or cytotoxic T-cell activity $[51,54,55]$.

\section{Antiviral drug targets}

Standard therapeutic compounds target the enzymes or receptors involved in essential viral functions. However, an alternative, complementary strategy is to focus on host cell factors like proteases as targets to arrest the development of 
the virus. Such an alternative approach reduces the likelihood of developing antiviral drug resistance and can target multiple viruses at a time. Despite this advantage, cytotoxicity and cellular side effects remain the significant drawbacks of targeting host cells $[56,57]$.

\section{Potential JEV drug targets}

- C protein The basic $11 \mathrm{kDa}$ C protein interacts with viral genomic RNA, forming the nucleocapsid (NC). The capsid folds into a dimer, in which each monomer contains four $\alpha$-helices. The $N$ and $C$ termini contain charged residues, of which the $C$-terminal region may be involved with RNA association $[58,59]$. The potential active site for binding the viral genome and nucleocapsid formation is the $\alpha 4-4$ ' site on the dimeric interface due to its coiledcoil-like structure near the $C$-terminal (Fig. 5A) [58, 60]. The dimerization of $\mathrm{C}$ protein is a crucial step in its association with genomic RNA. Identifying compounds that block capsid dimerization or capsid-genome interaction can help develop effective anti-JEV drugs [61].

- $\mathbf{M}$ and $\mathbf{E}$ proteins The prM and $\mathrm{E}$ proteins are the main constituents of the immature virion, and this characteris- tic arrangement prevents their premature budding. With the help of cellular serine protease furin, the immature particles undergo conformational changes in the $\mathrm{E}$ protein, and this reaction facilitates maturation. Dimeric E protein is the major surface component of the immature virion whose conformational changes during maturation result in the mature virion's formation $[59,62]$. The $\mathrm{N}$-linked site in Domain 1 (D1) of the E protein has been associated with the infectivity of the virion and interaction with the cellular receptors (Fig. 5D). Therefore, the location and presentation of the glycan linked to N154 indicate that it is the binding site for the receptor (Fig. 5D) [59, 63, 64]. Studies involving the structural analysis of $\mathrm{E}$ protein revealed three potential drug targets: the $\beta$-OG ligand-binding pocket, E-protein rafts in the mature virus, and $\mathrm{E}$ homotrimers $[59,62,65]$.

- NS2B-NS3 protease The serine protease domain in the $\mathrm{N}$-terminal of the NS3 protein (the catalytic triad residues being $\mathrm{His}^{51}-\mathrm{Asp}^{75}-\mathrm{Ser}^{135}$ ) was discovered by sequence comparison (Fig. 5C) [62, 66-68]. A heterodimeric complex of NS2B-NS3 was found involved in the cleavage of protease-sensitive sites-NS2A-NS2B, NS2B-NS3, NS3-NS4A, and NS4B-NS5. This proteo-
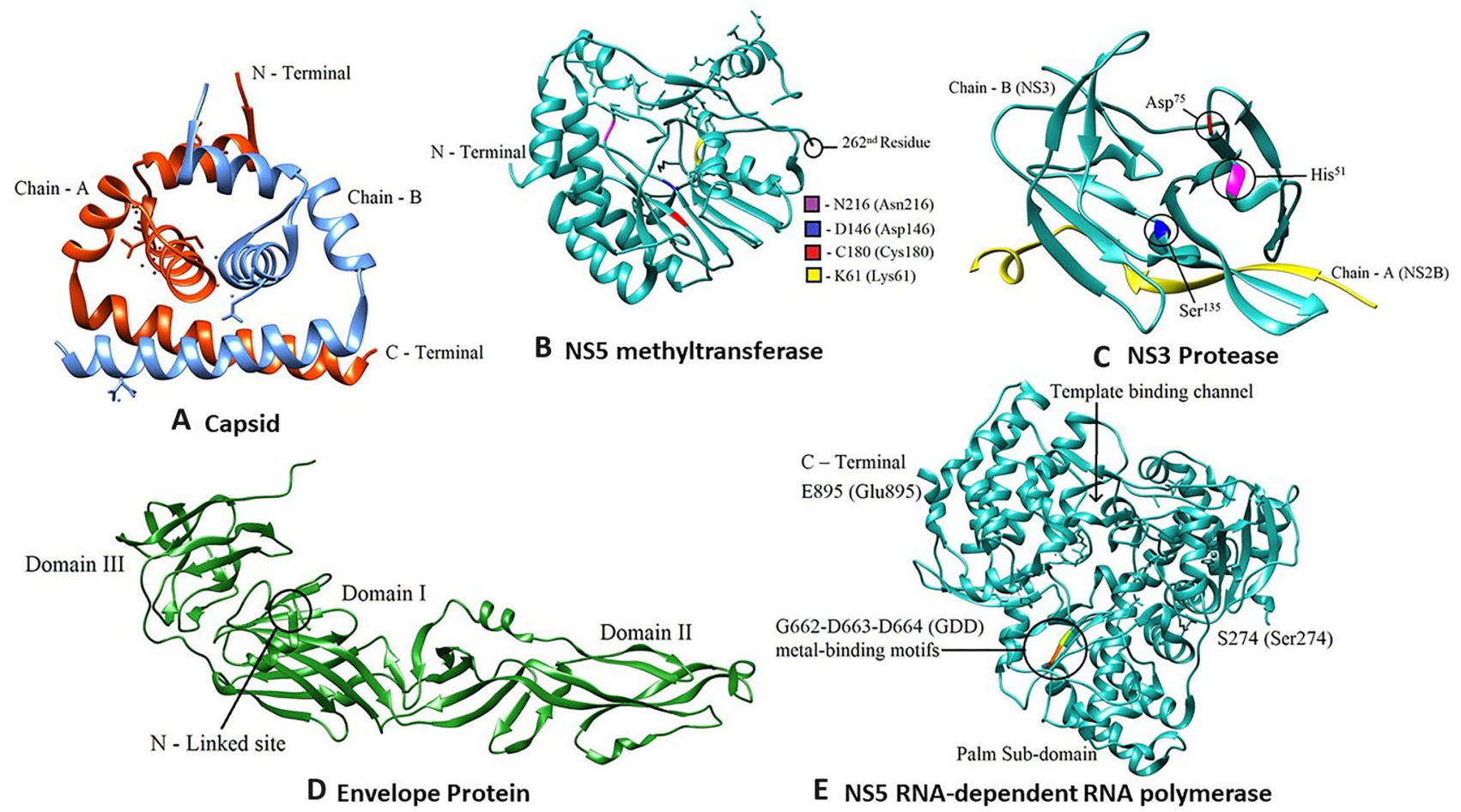

E NS5 RNA-dependent RNA polymerase

Fig. 5 A JEV capsid dimer. Chain A is highlighted in orange whereas chain B is highlighted in blue, B NS5 methyltransferase (The N-terminal of the NS5 protein: residues 1-262 in cyan and active site, containing a catalytic K61-D146-C180-N216 motif in yellow, blue, red, and magenta, respectively, C Crystal structure of the JEV NS2BNS3 protease (NS3 in cyan, NS2B in yellow, and the catalytic triad residues His51-Asp75-Ser135 in Magenta, Red, and Blue), D Crystal structure of JEV Envelope protein. JEV E protein possesses three domains characteristic of the flavivirus E protein, E JEV RdRp (G662-D663-D664 (GDD) metal-binding motifs are in red, orange, and yellow, respectively) 
lytic processing step is vital in the assembly of the viral replicase complex and is a promising therapeutic target $[62,67]$. An in-vitro study of the NS3 protein showed that it is not enzymatically active as a protease without the NS2B protein, contributed by the essential folding of the protein by NS2B. There have been no preclinical antiviral drug studies on the NS2B-NS3 complex despite the intensive research unveiling the structural properties of the molecule [69].

- NS3 helicase The structures of the $C$-terminal of the NS3 protease domain and NS3 helicase domain contain seven conserved motifs of NTPase and RNA helicases [44, 67]. The NS3 helicase facilitates the initiation of RNA synthesis and the melting of secondary structures. Resolving DNA duplexes formed during viral replication and separation of proteins bound to the viral genome is also regulated by NS3 helicase. RNA helicases have ATPase activity to facilitate the energy-dependent reaction of strand separation. Therefore, all NS3 helicases non-specifically hydrolyze nucleoside triphosphate to meet the energy requirement (hence known as "NTPase") [70].

The use of NS3 helicase as an antiviral drug target has been challenging compared to the other non-structural proteins because of the limited understanding of the mechanism of its action. The selectivity of the compounds that can inhibit the ATP binding site being cytotoxic is another problem in using NS3 helicase as a drug target. Recently newer tests in high-throughput screening platforms based on DNA substrates have been developed to replace time-consuming traditional assays for screening helicases [67].

- NS5 methyltransferase (MTase) The $N$-terminal of the NS5 protein has methyltransferase activity (residues 1-262) and adopts the S-adenosylmethionine (SAM) dependent methyltransferase fold, composed of four $\alpha$ helices surrounding central seven stranded $\beta$-sheets. The active site, containing a catalytic K61-D146-C180-N216 $(\mathrm{KDCN})$ motif, is positioned in the center of the $\beta$-sheet (Fig. 5B) [71].

NS5 MTase is an attractive drug target, and the focus on this drug target has increased in recent studies. One of the most crucial functions of NS5 MTase is the 5'-capping of nascent RNA. The $N$-terminal region of the NS5 protein methylates the $5^{\prime}$ guanine cap and the ribose $2^{\prime}-\mathrm{OH}$ position of the first transcribed nucleotide. Mutation studies on the NS5 MTase showed impaired viral replication, indicating that the enzyme plays an essential role in viral replication [72].

- NS5 RNA-dependent RNA polymerase (RdRp) The $C$-terminal of NS5 has polymerase activity (residues 273-900) and adopts a right-hand polymerase fold, consisting of fingers, palm, and thumb subdomains (Fig. 5E). The palm subdomain contains catalytic G662-D663-D664 (GDD) metal-binding motifs. JEV polymerase initiates RNA synthesis without the need for a primer [73].

NS5 RdRp at the $C$-terminal of the NS5 protein is one of the most promising and explored targets. This is primarily because of the absence of RNA-dependent RNA polymerase in humans. Nucleoside and non-nucleoside analogs have been extensively studied for targeting viral polymerase activity. The non-nucleoside compounds target the allosteric sites in the protein. Nucleoside analogs in the prodrug form are activated by phosphorylation to triphosphate. These active drug molecules inhibit the enzyme at the active site, restricting the chances of developing drug resistance; thus, are advantageous over non-nucleoside analogs [62, 73].

\section{Anti-Japanese encephalitis virus drugs}

\section{Nucleic acid-based antivirals}

The discovery of the microRNA application in inhibiting viral genome transcription and translation was revolutionary in developing novel antiviral drugs. The exceptionally high specificity of such nucleic acid-based drug molecules makes them compelling candidates for therapeutic applications (Table 2). MicroRNA-based drug candidates examined that in-vitro and in-vivo have shown promising results by providing partial or complete protection in mice against JEV. These drugs have been targeted against genes coding for the Membrane, Envelope, Capsid, NS1, NS3, and NS5 proteins. However, a drawback of these therapeutics is that they must be administered simultaneously during or before JEV infection. They also lacked specificity to multiple strains or different genotypes [11, 74, 75].

Nucleic acid derivatives with heterocyclic bases as side chains and noncyclic peptide-like backbones were found to bind irreversibly to their complementary sequences with high specificity. These derivatives, called peptide nucleic acids (PNAs), inhibited viral translation. Numerous PNAbased drug candidates with varying specificity have been tested since their discovery. PNAs conjugated with cellpenetrating peptides were used for the study to ensure efficient uptake in cells. These PNAs targeted the untranslated regions (UTRs) of the viral genome and studied their antiJE properties. The study revealed inhibition of the viral replication, which was attributed to the interference in genome cyclization induced by PNAs, highlighting their potential anti-JE activity [133]. 
Table 2 Anti-Japanese encephalitis virus drugs

\begin{tabular}{|c|c|}
\hline Antiviral drug & Target/mechanism \\
\hline \multicolumn{2}{|l|}{ Non-specific broad spectrum } \\
\hline Interferon $[11,47,76]$ & $\begin{array}{l}\text { Interferon-stimulating genes-create an antiviral state and trigger the } \\
\text { adaptive immune response }\end{array}$ \\
\hline Aloe-emodin [77] & Interferon and interferon inducers \\
\hline Ribavirin $[39,78-80]$ & $\begin{array}{l}\text { Inosine monophosphate dehydrogenase-inhibits the synthesis of } \\
\text { guanine nucleotides }\end{array}$ \\
\hline Minocycline $[42,43]$ & $\begin{array}{l}\text { Inhibits free oxygen radical generation resulting in reduced oxidative } \\
\text { stress }\end{array}$ \\
\hline Arctigenin $[50,52]$ & Anti-oxidative activity, anti-inflammatory activity \\
\hline Fenofibrate $[11,81]$ & Anti-oxidative activity, anti-inflammatory activity \\
\hline $\begin{array}{l}\text { Aspirin indomethacin } \\
\text { Sodium salicylate [82] }\end{array}$ & $\begin{array}{l}\text { Cyclooxygenase inhibitors; modulates intracellular MAP kinase path- } \\
\text { way following JEV infection }\end{array}$ \\
\hline Rosmarinic acid $[40,82]$ & Anti-inflammatory and/or anti-apoptotic activity \\
\hline Curcumin $[11,41]$ & $\begin{array}{l}\text { Anti-oxidative activity } \\
\text { Dysregulation of Ubiquitin-Proteasome system thus reducing the for- } \\
\text { mation of new viral particles }\end{array}$ \\
\hline Pentoxifylline $[11,79,83]$ & Interferes with the assembly and release of the virus \\
\hline Nitazoxanide $[59,84,85]$ & Targets early mid-stage of viral replication Activates eIF $2 \alpha$ \\
\hline Diethyldithiocarbamate (DDTC) $[86,87]$ & Anti-oxidative activity \\
\hline BCX4430 (Galidesivir) $[88,89]$ & C-nucleoside analog of adenosine \\
\hline Luteolin $[90,91]$ & Inhibits $\mathrm{E}$ protein synthesis \\
\hline Eflornithine $[88,90]$ & Enzyme-activated; an irreversible inhibitor of ornithine decarboxylase \\
\hline Tubacin [92] & Inhibits Histone deacetylases (HDACs) \\
\hline Astragali radix [35] & Non-specific mechanisms like anti-inflammatory activity \\
\hline Anisomycin $[82,93]$ & $\begin{array}{l}\text { Restores the function of the extracellular signal-regulated kinase (ERK) } \\
\text { and suppresses JEV-induced cytotoxicity }\end{array}$ \\
\hline Apoptozole $[90,94]$ & Inhibits the functioning of HSP70 protein \\
\hline Erythrosin B [95] & Inhibits flavivirus NS2B-NS3 protease \\
\hline Tilapia hepcidin (TH) 1-5 [96] & Anti-inflammatory and immunomodulatory activities \\
\hline Dehydroepiandrosterone (DHEA) [93] & ERK activation and upregulation of MAPK pathway \\
\hline \multicolumn{2}{|l|}{ Nucleic acid-based } \\
\hline siRNA (Gene silencing) & Domain II of E-protein [97] \\
\hline & NS5—coding Region [98] \\
\hline & Capsid 'C,' Membrane 'M,' NS3_coding sequence [99] \\
\hline & Envelope 'E,' NS3, NS4b_coding sequence [100] \\
\hline & $\begin{array}{l}\text { PrM, NS1, NS2A, NS2B, NS3, NS4A, NS4B, NS5—coding sequence } \\
\text { [100] }\end{array}$ \\
\hline & C, E, NS1, NS3, NS4B, NS5—coding sequence [99] \\
\hline Peptide nucleic acids [101] & 5' UTR, 3' UT of JEV genome \\
\hline Morpholino oligomers [102] & 5' UTR, 3' UT of JEV genome \\
\hline Rin-expanded ("Fat") nucleoside and nucleotide analogs $[62,103]$ & Inactivation of NS3 NTPase/helicase \\
\hline DNAzymes [45] & $3^{\prime}$ non-coding region of the JEV genome \\
\hline shRNA [100] & E gene, $\mathrm{C}$ and NS4b1 gene \\
\hline \multicolumn{2}{|l|}{ Replication cycle-based } \\
\hline Proteoglycans (Heparin sulfate, Chondroitin sulfate) [11, 104-106] & Interferes with the attachment and entry of JEV \\
\hline E-Protein Domain III binding peptide $[11,107,108]$ & Inhibits the interaction of E-protein with the cell receptor \\
\hline Surfactant modified nanoscale silicate platelet $[11,109]$ & Blocks viral adsorption to the cell \\
\hline Indirubin $[11,110]$ & Inhibits virus attachment \\
\hline Bovine lactoferrin $[11,111]$ & Binds to Heparin sulfate and prevents attachment \\
\hline Griffithsin $[11,112]$ & Binds to E-protein and prevents attachment \\
\hline 2-Deoxy-D-glucose and 3-deazauridine [35] & Interference with the synthesis of JEV glycoprotein, DNA, and RNA \\
\hline
\end{tabular}


Table 2 (continued)

\begin{tabular}{|c|c|}
\hline Antiviral drug & Target/mechanism \\
\hline $\begin{array}{l}\text { 2-Methylnaphtho[2,3-b] furan-4,9-dione } \\
\text { 2-(1-hydroxyethyl)-analog of naphtho[2,3-b] furan-4,9-dione 2-methyl- } \\
\text { 5(or 8)-hydroxyanalog naphtho[2,3-b] furan-4,9-dione [35] }\end{array}$ & $\begin{array}{l}\text { Inhibits replication through inhibition of viral RNA and protein synthe- } \\
\text { sis }\end{array}$ \\
\hline Suramin [35] & $\begin{array}{l}\text { Inhibits replication by blocking the production of viral E and NS3 } \\
\text { proteins }\end{array}$ \\
\hline Lactoferrin [35] & $\begin{array}{l}\text { Inhibits JEV entry into the host cell by binding directly to the virus } \\
\text { particle or } \\
\text { to membrane-bound heparan sulfate }\end{array}$ \\
\hline PI 88 [35] & $\begin{array}{l}\text { Causes steric hindrance to JEV attachment to host cells; may possess } \\
\text { immunomodulatory activity }\end{array}$ \\
\hline MCPIP1 ribonuclease $[11,113]$ & $\begin{array}{l}\text { Targets JEV genome. It has RNase activity and thus inhibits viral } \\
\text { replication }\end{array}$ \\
\hline Kaempferol $[11,114]$ & Binds to JEV frameshift site RNA (fsRNA) and inactivates the virus \\
\hline Methyl- $\beta$-cyclodextrin [35] & $\begin{array}{l}\text { Disrupts lipid raft formation by depleting cholesterol; inhibits replica- } \\
\text { tion and viral entry into host }\end{array}$ \\
\hline Filipin III [35] & Chelates cholesterol; inhibits replication and viral entry into host \\
\hline Bafilomycin A1 [35] & $\begin{array}{l}\text { Inhibits vacuolar-type proton pump; inhibits } \mathrm{pH} \text {-triggered membrane } \\
\text { fusion of endocytosed JEV, thereby preventing replication }\end{array}$ \\
\hline Dehydroepiandrosterone [35] & $\begin{array}{l}\text { Modulates signaling pathways of extracellular signal-regulated protein } \\
\text { kinase }\end{array}$ \\
\hline $\begin{array}{l}\text { N-methylisatin-beta-thiosemicarbazone derivative (SCH } 16)[11,78 \text {, } \\
115]\end{array}$ & Inhibits early translation \\
\hline SK-12 protein $[69,116]$ & Inhibits NS2B-NS3 serine protease \\
\hline Recombinant NS3 protein motif-IV [117] & Inhibits NS3 NTPase/helicase \\
\hline $\begin{array}{l}\text { N-nonyl-deoxynojirimycin (NN-DNJ), (Imino sugar derivative) [11, } \\
44]\end{array}$ & $\begin{array}{l}\text { Inhibition of cellular glycoprotein processing } \alpha \text {-glucosidase enzymes } \\
\text { which leads to misfolding of viral proteins }\end{array}$ \\
\hline FGIN-1-27, Cilnidipine [118] & Inhibits viral replication \\
\hline Manidipine $[11,118]$ & Inhibits NS3 Helicase \\
\hline Carrageenan (sulfated polysaccharide) [119] & Inhibits entry into host cells \\
\hline Temoporfin [120] & Inhibition of the interactions between viral NS2B and NS3 proteins \\
\hline NSC 12155 [121] & Inhibits NS5 methyltransferase activity \\
\hline $2 \mathrm{~F} 2$ and $2 \mathrm{H} 4$ (monoclonal antibodies) [122] & Blocks attachment of the virus to its receptor \\
\hline Lonafarnib [123] & Inhibits virus replication (viral entry) \\
\hline Nitroxoline [123] & Inhibits virus replication \\
\hline Cetylpyridinium chloride [123] & Inhibits virus replication \\
\hline Cetrimonium bromide [123] & Inhibits virus replication \\
\hline Hexachlorophene [123] & Inhibits virus replication \\
\hline Belladonna [124] & $\begin{array}{l}\text { Reduces caspase } 3 \text { and } 8 \text { enzymatic } \\
\text { Activity NS3Protein and reduce its expression }\end{array}$ \\
\hline Pokeweed antiviral protein [125] & Depurination of viral RNAs \\
\hline Furanonaphthoquinone [126] & Inhibits the expression of viral proteins and also genomic RNA \\
\hline Quercetin [127] & Intracellular virucidal activity, and Inhibits adsorption \\
\hline Baicalein [127] & Intracellular virucidal activity, Inhibits adsorption \\
\hline Amphotericin B [128] & Inhibits viral replication and/or the synthesis of viral proteins \\
\hline \multicolumn{2}{|l|}{ In-silico modeling-based } \\
\hline Ivermectin $[11,129]$ & NS3 Helicase Inhibitor \\
\hline 4-Hydroxy panduratin A [130] & NS2B-NS3 protease inhibitor \\
\hline Bortezomib [131] & Targets JEV genome \\
\hline Mycophenolate [132] & E-protein inhibitor \\
\hline
\end{tabular}

$C$ capsid, $M$ membrane, $E$ envelope, $N S$ non-structural, $p r M$ premembrane, $M A P K$ mitogen-activated protein kinases, $J E V$ Japanese Encephalitis Virus, eIF2a eukaryotic Initiation Factor 2a, HSP70 Heat Shock Proteins 70, ERK extracellular signal-regulated kinases, UTR untranslated region, NTPase nucleoside triphosphatase, DNA deoxyribonucleic acid, RNA ribonucleic acid, siRNA small interfering RNA, shRNA short hairpin RNA, DNAzymes deoxyribozymes, $f_{s} R N A$ frameshift site RNA 


\section{Viral replication cycle-based antivirals}

Theoretically, each step in the JEV replication cycle is a potential target for antiviral drug development. A compound targeting various stages-from the binding of the virus to the cellular receptors to genome replication, protein translation, maturation, and release-can inhibit the development of the virus. Numerous approaches were aimed at preventing the initial attachment of the virus to the cellular receptors. Heparan sulfate was found to be an essential cellular receptor and was considered a potential drug target. Cell-free heparin sulfate derivatives were studied in in-vitro and in-vivo systems, where these molecules exhibited partial protection against JEV infection [104]. RNA replication has been a potential drug target primarily because of the several factors governing it. The nuclease domain of a protein called Monocyte chemoattractant protein 1-induced protein 1 (MCPIP1) expressed antiviral activity against JEV in-vitro. MCPIP1 may target multiple JEV RNA sites and inhibit replication by interacting with RNase, RNA binding, and oligomerization $[113,134]$. A plant-derived protein called Pokeweed antiviral protein isolated from Phytolacca Americana hindered viral replication in-vitro. This protein resulted in the depurination of the viral RNA. An in-vivo study involving the intraperitoneal administration of this antiviral protein to mice revealed partial protection against JE [9].

\section{In-silico modeling-based antivirals}

Recent advances in structural virology have helped in obtaining high-resolution images of viral proteins. These include NS3 C-terminal (NTPase/helicase catalytic domain) [135], E protein [64], NS5 [136], capsid protein [61], and NS2B-NS3 (JEV protease) [137]. Among these proteins, most antiviral drug candidates have been targeted against NS3, NS5, and E proteins primarily because of the essential role they play in the course of the infection [11].

\section{Antiviral susceptibility screening}

The recent advancement in drug discovery has allowed researchers to avoid time-consuming trial-and-error methods, which, in most cases, prove costly. NMR and crystallography, computational advances in virtual screening, and the development of high-throughput screening (HTS) platforms have built the foundation of structure-based drug screening techniques. Rational drug screening (RDS) requires detailed knowledge of drug targets and drugs. It essentially involves a detailed analysis of the three-dimensional interaction between the target and the drug. A compound is selected and tested for its specific activity against the virus under consideration. This selection is based on the well-characterized understanding of the particular viral target. RDS technique requires a sound knowledge of structural chemistry and biology as the drug's activity depends on the chemical interactions between the viral target and the drug [138, 139].

\section{Computational screening studies}

The development of a virtual screening platform was one of the most remarkable advancements that enabled the in-silico screening of multiple drugs with several targets simultaneously. The advances in structural chemistry like NMR spectroscopy techniques and crystallography, along with high-throughput protein purification, paved the way for the development of computational analysis of drug-protein and protein-protein interaction. Virtual screening (VS) techniques are mainly employed for 'hit' identification and 'lead' optimization. Computational screening is a direct and cost-effective way for rational drug screening compared to conventional high-throughput screening methods. Virtual screening involves ligandbased and structure-based methods. When the structural information is unavailable for targets, but the active ligand molecules are known, the ligand-based techniques are employed. Molecular docking is an example of structurebased drug design, where the complete structural details regarding the target and the drug molecule are known [140].

Molecular docking is a virtual screening technique that calculates the interaction energy between any two molecules. Docking employs algorithms like distance geometry methods, molecular dynamics, Monte Carlo simulation, fragment-based search, etc., to help understand the molecular interactions better. The best orientation for ligand binding to form a complex with a minimum energy of a molecule is found using the molecular docking technique. The ligand binds to the protein's active sites, predicted by the search algorithms used [141].

Docking plays a vital role in computational drug design. Considerable efforts have been made towards improving docking algorithms due to the spectrum of molecular docking applications. The docking results are formalized by a statistical scoring function based on the interacting energy of the molecules and are called the docking score. Visualization of the bound ligand is done using visualizing tools like Pymol [141-143], Chimera, etc. [144, 145]. These 3D visualizations can help draw a better inference of the best fit of the ligand [138]. Several drugs have been screened for the Japanese encephalitis virus targets using various molecular docking programs like SYBYL, modeler, AutoDock, GOLD Suite (Genetic Optimization for Ligand Docking), etc. (Table 3). 
Table 3 Docking programs used in virtual screening of compounds

\begin{tabular}{lll}
\hline Docking program & Antiviral drug & Target \\
\hline SYBYL8.0 [132] & Compounds screened from Specs compound library & NS3 helicase/nucleoside \\
AutoDock 4.2 [11, 126] & 4-hydroxy panduratin A & NS2B-NS3 protease \\
AutoDock 4 [83, 127] & Ivermectin & NS3 helicase \\
& Antiviral molecules and their analogs from the NCBI Pub-Chem com- & E protein \\
& pound database were identified for their drug-like properties using the & \\
Lipinski filter & NS3 protein \\
AutoDock Vina [138, 140,146] & Novel ligands developed with v1.2 software & RdRp protein \\
modeler 9.10 [132] & 43 bioactive bioflavonoids reported in Azadirachta indica & E-protein \\
GOLD Suite 5.1 [142] & Mycophenolate & NS3 helicase/nucleoside \\
GLIDE [147] & Compounds screened from the ZINC database & JEV NS3 helicase, \\
& Phytoconstituents of the Arisaema & NS2B-NS3 protease, \\
& & and NS5 \\
Molegro Virtual Docker (MVD) [121] & Atropine and scopolamine & NS3 protein \\
iGEMDOCKv2.1 [148] & Aminoglycoside and Tetracycline group of compounds & NS3 helicase / nucleoside \\
\hline
\end{tabular}

$N S$ non-structural, $E$ envelope, $R d R p$ RNA-dependent RNA polymerase, JEV Japanese encephalitis virus

\section{High-throughput screening}

High-throughput screening (HTS) enables quick analysis of a series of chemical compounds. This technique is one of the most modern technologies employed in antiviral drug screening. This method helps in the characterization of affinities of biological structures. HTS includes a series of screening and assaying of biological modulators and effectors against specific targets. HTS assays can be used to screen various kinds of libraries, including drugs, peptides, proteins, and genomics. The principal objective of the HTS technique is to make a fast-track screening process for analyzing multiple drugs at a time. This technique enables screening at a rate that may exceed a few thousand compounds per day. This property of HTS is of utmost importance, because many novel compounds are being synthesized daily by combinatorial chemical synthesis. HTS technology significantly reduces the cost of research. Target identification followed by the preparation of the reagent and compound, assay development, and screening drug libraries is essential in HTS [149].

The compounds first undergo a primary screening, after which those compounds that give a positive result are considered as 'hits' and undergo secondary testing. The primary screening is less quantitative compared to traditional assays and calculates $\mathrm{IC}_{50}$ values (50\% inhibitory concentrations of the compound). Secondary tests are usually biochemical tests that are more sensitive and specific to antiviral activity. HTS platform employs miniaturized cell-based assays or biochemical assays [149]. Drug libraries can be screened at a fast pace using assays that have been performed in an HTS platform to screen inhibitors of JEV infection [46]. Cell viability assays, such as Cell titer-Glo Luminescent
Cell Viability Assay [117], MTT assay [150], LDH assay $[102,111]$, XTT assay [127, 150], FRET assay [118, 142], etc., have been performed in an HTS platform to analyze parameters such as cytotoxicity, antiviral activity, radical, and oxygen production.

\section{Plaque reduction neutralization assay}

The plaque reduction assay (PRA), first described in the 1950 s, is currently a standard method for in-vitro determination of antiviral drug susceptibility. PRA is the most commonly reported technique that sets a benchmark of comparison for many novel methods [151]. The design of the PRA measures the drug's effects on the infectivity of the virus by plating the virus-drug mixture on a virus-susceptible cell line. Overlaying the cells with semi-solid media restricts the spread of the progeny virus [152]. Each virus particle multiplies under conditions that result in a localized area of infected cells or 'plaque.' The plaques are revealed either as areas of dead/destroyed cells detected by general cellular stains or as areas of infected cells detected by immunostaining [153]. The initial concentration of the virus in the stock is calculated from the number of plaques, and the total virus infectivity is calculated. The virus to be used for PRA is quantified initially by plaque assay. The antiviral drug is serially diluted to estimate the endpoint titers for each drug concentration [152]. However, PRA requires viral titration and prolonged incubation until the viral cytopathogenic effect is visible. This method is laborious, subjective, and time-consuming [151]. Plaque reduction assay being a standard phenotypic susceptibility test has been used for screening antiviral activity of molecules like curcumin [41], 
tripeptide NSK [154], griffithsin [112], and other drug candidates [105, 107].

\section{Other antiviral drug screening techniques}

\section{Quantitative real-time PCR (qPCR)}

The qPCR is a PCR-based technique that integrates amplification of a target DNA sequence with quantification of its concentration. Quantification of nucleic acids by real-time PCR is done by two standard methods: relative quantification and absolute quantification. Absolute quantification employs a calibration curve plotted with the help of DNA standards to give the exact number of target DNA molecules. This type of quantification dictates that the amplification efficiency of the sample and the standard is the same. When internal reference genes are used to determine fold differences in the target gene expression, it is referred to as relative quantification [155-158]. The assay measures inhibition of viral DNA production by quantification of viral DNA using the TaqMan technology and assesses the effect of the drug on the virus $[112,155,159]$.

\section{Focus-reduction assay}

The foci assay is a variation of the plaque assay, where the addition of a virus-specific primary and fluorescent-labeled secondary antibody is used to quantify the virus. After adsorption and gene expression, primary and secondary antibodies are added and incubated. The immobilized virus particles bound to the antibodies will form fluorescent foci, which can be observed under a microscope at an appropriate wavelength. A standardized amount of virus determined by the focus-forming assay is used for the focus reduction assay. The virus stock is titrated and is expressed in focus-forming units per milliliter $[160,161]$. A variation of this technique uses insoluble dye bound to a secondary antibody instead of the fluorescent molecule. It is a practical cell-based antiviral drug susceptibility test [118]. A focus reduction assay demonstrated the application of chondroitin sulfate as an antiviral against JEV [105].

\section{High content imaging}

High content imaging is a type of HTS that employs virusspecific fluorescent labeling and a competent imaging platform to screen potential molecules for their antiviral activity. It is a relatively recent advancement in screening drug libraries and is highly efficient due to its accuracy in labeling the viral component. Immunofluorescent staining or construction of JEV virus expressing GFP reporter gene which generates fluorescent signal can be utilized for this assay [123, $162,163]$. Immunofluorescent staining involves the use of a
JEV specific primary antibody (anti-JEV prM) and fluorescent-labeled secondary antibody (DyLight 488-labeled antibody). Cell monolayers infected with JEV (strain-AT31) are treated with the drug molecules and incubated. After $23 \mathrm{~h}$ of incubation, the cells are fixed and stained with the primary and fluorescent-labeled secondary antibody [162]. The reporter JEV genome is constructed using a wild-type JEV (pACYC-JEV-SA14) as the foundation. The eGFP (enhanced green fluorescent protein) gene is incorporated in the capsid region of the JEV genome, and the capsid protein of the resultant reporter virus emits fluorescent signals. The reporter virus can infect the cell monolayers and treat the drug molecules [123, 163].

The number of cells emitting fluorescence signals are then read by high-content imaging platforms such as Cell Voyager 7000S, PerkinElmer high-content screening system, and Operetta high-content imaging system. The recorded readings are then examined using analytical software (Harmony 3.5, GraphPad Prism 5.0) to quantify each drug molecule's infectivity and effectiveness [123, 162, 163].

\section{Co-immunoprecipitation}

Co-immunoprecipitation (Co-IP) is an efficient method used to study protein-protein interactions selectively. Proteins or ligands bound to a specific target protein are indirectly captured with the help of viral target protein-specific antibodies. Co-IP is an extension of immunoprecipitation. Other molecules such as the antiviral drug compound bound to the target protein by native interactions are also precipitated [164]. This modification of the co-immunoprecipitation technique that focuses on binding the drug molecule to the target viral protein enables it to be used as an efficient drug susceptibility screening tool $[100,159]$. N-nonyl-deoxynojirimycin (NN-DNJ) interaction studies with cellular targets for studying anti-JEV properties were done using co-immunoprecipitation [44].

\section{Virus yield assay}

The virus yield reduction assay is a powerful technique for evaluating the efficacy of antiviral compounds; it is not routinely utilized as the process is quite laborious [165]. In this assay, different susceptible cells of the given virus are grown in 24-well plates and are infected with the virus in the presence of different concentrations of the compounds, at least two wells per concentration. After incubation in the cell, supernatants are collected, and the virus yields are determined by plaque formation in a susceptible cell line [148]. The antiviral activities of chemical compounds such as mycophenolic acid and CW-33 analogs were assessed using Virus Yield Assay [166, 167]. 


\section{In-vivo antiviral studies using animal models}

Animal models are frequently used to study antiviral drug candidates and can help better understand the mechanism of the drug intervention. In-vivo helps to understand the pathogenesis of an ongoing infection. They are also employed to get a much clearer picture of the cytotoxicity profile of the drug candidate in a clinical scenario. The mouse model has been the most preferred and widely used for studying viral encephalitis, employed for testing the effectiveness and safety of viral vaccines and therapeutics. A high degree of susceptibility to laboratory strains of JEV, similarity in disease presentation and virus tropism with humans, and availability of large numbers of animals for experimental purposes, etc., make the mouse model suitable for in-vivo studies [168]. Commonly observed neurological symptoms like poor pain response, piloerection, restriction of movements, body stiffening, limb paralysis, and whole-body tremor greatly resemble the symptoms in humans and are predictive of the disease. Thus, these signs often trigger intervention and other triggers such as the virus titer, virus antigen, and nucleic acid in brain samples. Molecular events caused by JEV infection in mouse brains have also been identified as triggers for intervention and are characterized by quantitative mass spectrometry studies. In infected mouse brains, several upregulated interferon-stimulated genes and induced inflammatory cytokines, such as IFN- $\gamma$, IL-6, TNF$\alpha$, and TGF- $\beta$ in infected mouse brains, have served as biomarkers in studying JEV pathogenesis and the efficacy of treatment strategies [169-171].

Most of the studies on antivirals against JEV utilized neonates or adolescent (4- to 5-week-old) BALB/c mice, which, when infected with a lethal dose of JEV, exhibit a distinct pattern of infection. Consistent propagation of JEV in the brain to the levels necessary for antiviral drug screening was only achieved in neonate mice (1-week-old) inoculated intracerebrally or intravenously [172, 173]. An alternative was a mouse-adapted isolate of JEV (JEV-S3), which was used to develop a robust mouse model of JEV infection in adolescents (3-4 weeks old) C57BL/6 mice intraperitoneal route. The model developed clinical symptoms, with the virus entering and replicating vigorously in the brain. Triggers such as proinflammatory proteins were upregulated, eventually leading to death. Interestingly, BALB/c mice (3-4 weeks old) also exhibited identical susceptibility to JEV-S3 [169]. Therefore, the JEV-S3-infected animal model would help understand details of the JEV pathogenesis and screening antiviral molecules.

Drug candidates like griffithsin [112], tripeptide NSK [154], and imino sugars [44] were tested for their antiviral activity in mouse models. These procedures involved selecting 3-7-month-old mice (BALB/c, ICR), segregated into control and test groups. A non-cytotoxic concentration of the drug and a lethal dose of the virus was administered intraperitoneally in a peripheral challenge model. The drug was administered orally [44] as well as via injection intraperitoneally $[112,154]$. After a period of observation for the various symptomatic triggers to manifest in controls, the mice were sacrificed randomly from each group, and brain samples were collected. These samples were further analyzed using plaque assay and western blot assay for quantification. The virus titer, which indicates the extent of virus multiplication in the drug's presence and absence, is a standard trigger utilized for in-vivo antiviral studies for JEV.

\section{Discussion}

Japanese encephalitis (JE) caused by the JE virus (JEV) is one of the leading causes of viral encephalitis localized predominantly in the Asian region. Though JE is endemic to many parts of Asia, recently, several cases have been reported from areas such as northern Australia and the western Pacific region, where the threat was previously unknown [1]. Around 2 billion people inhabit areas experiencing significant risk of JEV [5]. Factors like population explosion, rapid globalization, migration, climatic shift, and large-scale escalation in rice cultivation have resulted in the spread and rise of JEV in the recent decade [5, 23]. Speculations that JEV can become a global pathogen in the future, causing worldwide pandemics, cannot be overlooked.

Currently, the efforts to control JE in India and other JEV endemic Asian countries are focused on widespread vaccination programs. The disease is preventable by vaccination and vaccination drives which have shown significant results [174]. However, the prevalence of neurological complications related to JEV remains significantly high, with death rate risks as substantial as 60\% [140]. This points towards the urgent requirement to identify and develop specific therapeutic interventions to treat the infection. Although there have been many in-silico, in-vitro, and in-vivo studies dedicated to discovering anti-JEV compounds, the promise of a safe, effective, and affordable drug is afar. This challenge is particularly significant for JEV endemic countries, explicitly developing countries that suffer from low vaccine coverage.

Antiviral therapeutics indicate drugs or various therapies effective in treating virus infections in patients. Antiviral treatments must either inhibit the multiplication of the virus or be active within the infected cell [175]. Usually, antiviral drug therapies have been found to impede virus replication through different potential mechanisms. Therefore, therapeutics include drugs, which would work to clear the infection when administered earlier in infection, i.e., immediately post-exposure or sometimes even a few days later post-infection. 
Many treatment options have been explored, ranging from interferon therapy to clinical trials with broadspectrum antiviral drugs such as ribavirin. However, none of these have successfully treated JE $[39,47]$. The shift in screening approaches from available antiviral drugs towards naturally occurring molecules was remarkable. Natural molecules such as rosmarinic acid (phenolic compound) and arctigenin showed protection in mice by markedly increasing proinflammatory mediators in the brain and decreasing JEV (GP78 strain)-induced neuronal apoptosis, caspase activity, and microglial activation. A broadspectrum tetracycline antibiotic called minocycline also exhibited antiviral activity against JEV by decreasing JEVinduced neuronal apoptosis and proinflammatory activity in the brain in an in-vivo study $[40,50,176]$.

$N, N$-methylisatin- $\beta$-thiosemicarbazone, a chemical derivative, and $\mathrm{N}$-nonyl-deoxynojirimycin, a glucosidase inhibitor of the endoplasmic reticulum, completely inhibited JEV replication in-vitro [11, 78, 115]. Innovative ideas employing RNA interference techniques have also been tried. Before or after the viral challenge, a single intracranial administration of lentivirus-delivered short hairpin RNA or lipid-complexed small interfering RNA (siRNA) protected lethal encephalitis [97].

A major challenge faced while studying many of these drugs was that these drugs were effective when administered before or immediately after the infection. Generally, it takes a considerable amount of time to onset symptoms in a clinical scenario, depending on incubation time, immune response, etc. Treatment is usually started after the disease has set in. Hence, there is a need for antiviral drugs effective against JEV prophylactically and therapeutically. Although in-vitro and in-silico studies can give information about a drug's potential antiviral nature along with evidence of its cytotoxicity profile, a significant limitation associated with these study results is the varied translation of the effects in an in-vivo study. On the other hand, in-vivo studies using laboratory animals such as mice, and rabbits, mimicking a natural infection, may fail to predict the desired efficacy in humans.

JEV can affect the CNS in about 4-6 days after infection. Therefore, even with early diagnosis, there is a sufficient risk of CNS invasion by the virus before antiviral treatment is initiated [14]. Since the drugs cannot cross the blood-brain barrier, treatment in such cases will be ineffective. Therefore, an efficient drug delivery system is a requisite to ensure the activity of anti-JE drugs [177]. Lipid solubility of the BBB is an important feature that allows passive diffusion into the BBB. Specific chemical modification of the drug molecule may impart more permeability to the drug [178]. This modification limits the drug selectivity and distribution across the tissue. A prodrug and nanoparticles are alternate methods for better drug delivery and tissue specificity $[177,178]$.

Several drug molecules have been demonstrated to have significant anti-JEV activity in-vitro and in animal models; some of them widely used for treating other conditions [13]. The majority of these studies suggested a timeline of 5-6 days post-infection for initiating the treatment based on the prognosis of the disease in animal models. On average, $70-100 \%$ survival was observed with most of these therapeutics administered at the time of or shortly after JEV infection. However, molecules like minocycline, etanercept, and pentoxifylline proved effective when administered 5-6 days post-infection. [79, 179, $180]$. Another example is the conferred protection provided by the anti-JEV monoclonal antibody on day five after infection [181]. None of the trials with therapeutics on Japanese encephalitis have successfully demonstrated a beneficial outcome to date. Besides, many approaches remain untested, which can be attributed to the delayed and incomplete understanding of the disease pathogenesis and treatment options in humans, despite advances in our comprehension of the disease mechanistic gathered from preclinical studies.

In the face of no effective drugs available for the treatment of JEV infection, it is essential to establish an efficient antiviral screening system to develop antiviral drugs. High-throughput screening (HTS) of antiviral drugs is a highly promising screening strategy, which usually employs two different approaches. One approach focuses on specific viral proteins targeted through in-vitro functional assays in a high-throughput platform. The latter uses in-vivo cellular antiviral assays in a high-throughput platform. Although the former gives a more simplistic setup, the second approach is broader and has lesser limitations. One efficient antiviral screening system was developed based on in-vivo cellular antiviral assays. It is involved the construction of reporter viruses from wild-type (WT) viruses, which can be used to isolate and understand antiviral drugs targeting the complete infection cycle. RlucJEV [123], Rluc-DENV [182], and eGFP-DENV [183] are examples of reporter flaviviruses developed for different research purposes.

Another example is an eGFP-JEV-based assay in a highthroughput platform employing an eGFP gene (eGFP-JEV) in a JEV reporter virus to screen 1443 compounds from an FDA-approved drug library. Sixteen drugs inhibiting JEV infection were identified, of which five drugs offered the potential for development as new therapies for the treatment of JEV infection [123]. The use of such novel systems in identifying JEV inhibitors may expedite the process of antiviral drug development considerably, thereby indicative of future advancements. 


\section{Conclusion}

Several new anti-flaviviral molecular targets and strategies have been defined with the advent of scientific research. Targeting viral proteins is one of the most attractive antiviral strategies and is vastly studied. These proteins exclusive to the virus allow the high specificity of the drug without affecting the host organism. The E and NS5 proteins of flaviviruses have proven promising targets for future drug design. Crystal structure determination of these proteins, especially the enzymatically active domains, provides information on their biochemical properties. In addition, the three-dimensional crystal structures of these proteins will facilitate the design of specific inhibitors with properties to alter the kinetics, subcellular localization, and regulation of the viral proteins. Focusing on the experimental studies to understand the physicochemical and biochemical properties of non-structural proteins of flaviviruses such as NS2B and NS3 also be highly useful. Crystallography-based models can also be used to study the protein substrate interaction. Advanced molecular biology knowledge and improved technological resources have rendered newer high-throughput anti-flaviviral drug screening pathways. Projects using the mega-computing power of the Autodock virtual docking program and several molecular dynamic programs have shown significant promise in anti-flaviviral drug research by helping identify drug-like molecules based on binding calculations mean-field molecular dynamics algorithms [165].

Different compounds isolated naturally or derived synthetically have exhibited targeted viral inhibition and significant antiviral properties. However, further research is quintessential to exploit the potential of these compounds to be developed into anti-JEV drugs. Despite extensive testing for anti-JEV activity through both in-vitro and in-vivo studies, none of these compounds have successfully exhibited a significant outcome in advanced studies. Accounting for the considerable percentage of JEV outbreaks occurring in developing countries, the need for effective, cheap, and readily available drugs is inevitable, besides increasing the vaccine coverage to overcome the challenge posed by JEV completely. Over the years, a better understanding of immunology, JEV pathogenesis, and replication mechanisms has aided in searching for novel anti-JE candidate drugs. However, awareness of the need for extensive research to deal with JE is still lacking worldwide. As the requirement for an anti-JEV drug is on the rise and as the search for antivirals for other flaviviruses accumulates research strategies for this work, several drug candidates can be expected to be soon evaluated in human clinical trials in the near future.

Acknowledgements We would like to thank the Manipal Institute of Virology, Manipal Academy of Higher Education, Manipal for extending all the support in drafting this article.
Author contributions All authors contributed to the study's conception and design. Material preparation, data collection, and analysis were performed by SJ, PPM, AAAS, UN, and NBN. The first draft of the manuscript was written by Shaun Joe and all authors commented on previous versions of the manuscript. All authors read and approved the final manuscript.

Funding Open access funding provided by Manipal Academy of Higher Education, Manipal.

\section{Declarations}

Conflict of interest The authors declare that they have no conflict of interest.

Open Access This article is licensed under a Creative Commons Attribution 4.0 International License, which permits use, sharing, adaptation, distribution and reproduction in any medium or format, as long as you give appropriate credit to the original author(s) and the source, provide a link to the Creative Commons licence, and indicate if changes were made. The images or other third party material in this article are included in the article's Creative Commons licence, unless indicated otherwise in a credit line to the material. If material is not included in the article's Creative Commons licence and your intended use is not permitted by statutory regulation or exceeds the permitted use, you will need to obtain permission directly from the copyright holder. To view a copy of this licence, visit http://creativecommons.org/licenses/by/4.0/.

\section{References}

1. Campbell G, Hills S, Fischer M, et al. Estimated global incidence of Japanese encephalitis. Bull World Health Organ. 2011;89:766-74.

2. Saxena SK, Agrawal PT, Nair MPN. Japanese encephalitis: a neglected viral disease and its impact on global health. In: Saxena SK, editor. Trends Infect Dis [Internet]. InTech; 2014 [cited 2021 Dec 20]. http://www.intechopen.com/books/trends-in-infec tious-diseases/japanese-encephalitis-a-neglected-viral-disea se-and-its-impact-on-global-health.

3. Basu A, Dutta K. Recent advances in Japanese encephalitis. F1000Research. 2017;6:259.

4. Ricklin ME, García-Nicolás O, Brechbühl D, et al. Vector-free transmission and persistence of Japanese encephalitis virus in pigs. Nat Commun. 2016;7:10832.

5. Gould EA, Solomon T, Mackenzie JS. Does antiviral therapy have a role in the control of Japanese encephalitis? Antiviral Res. 2008;78:140-9.

6. Dutta K, Rangarajan PN, Vrati S. Japanese encephalitis: pathogenesis, prophylactics and therapeutics. Curr Sci. 2009;98:10.

7. Erlanger TE, Weiss S, Keiser J, et al. Past, present, and future of japanese encephalitis. Emerg Infect Dis. 2009;15:1-7.

8. Knipe D, Howley P. Fields virology. 6th ed. 2013.

9. Wang X, Li S-H, Zhu L, et al. Near-atomic structure of Japanese encephalitis virus reveals critical determinants of virulence and stability. Nat Commun. 2017;8:14.

10. Vannice KS, Hills SL, Schwartz LM, et al. The future of Japanese encephalitis vaccination: expert recommendations for achieving and maintaining optimal JE control. Npj Vaccines. 2021;6:82.

11. Ishikawa T, Konishi E. Potential chemotherapeutic targets for Japanese encephalitis: current status of antiviral drug 
development and future challenges. Expert Opin Ther Targets. 2015;19:1379-95.

12. Muller DA, Young PR. The flavivirus NS1 protein: Molecular and structural biology, immunology, role in pathogenesis and application as a diagnostic biomarker. Antiviral Res. 2013;98:192-208.

13. Turtle L, Solomon T. Japanese encephalitis-the prospects for new treatments. Nat Rev Neurol. 2018;14:298-313.

14. Yun S-I, Lee Y-M. Early events in Japanese encephalitis virus infection: viral entry. Pathogens. 2018;7:68.

15. Appaiahgari MB, Abdin MZ, Bansal KC, et al. Expression of Japanese encephalitis virus envelope protein in transgenic tobacco plants. J Virol Methods. 2009;162:22-9.

16. Adapted from "Japanese Encephalitis Virus Replication", by BioRender.com (2021). https://app.biorender.com/biorendertemplates.

17. Utama A, Shimizu H, Morikawa S, et al. Identification and characterization of the RNA helicase activity of Japanese encephalitis virus NS3 protein. FEBS Lett. 2000;465:74-8.

18. Konishi E, Mason PW. Proper maturation of the Japanese encephalitis virus envelope glycoprotein requires cosynthesis with the premembrane protein. J Virol. 1993;67:1672-5.

19. Ghosh D, Basu A. Japanese encephalitis-a pathological and clinical perspective. PLoS Negl Trop Dis. 2009;3:e437.

20. Solomon T. Neurological aspects of tropical disease: Japanese encephalitis. J Neurol Neurosurg Psychiatry. 2000;68:405-15.

21. Kumar S, Nyodu R, K. Maurya V, et al. Pathogenesis and Host Immune Response during Japanese Encephalitis virus infection. In: K. Saxena S, Prakash H, editors. Innate Immun Health Dis [Internet]. IntechOpen; 2021 [cited 2021 Dec 20]. https://www. intechopen.com/books/innate-immunity-in-health-and-disease/ pathogenesis-and-host-immune-response-during-japanese-encep halitis-virus-infection.

22. Symptoms \& Treatment | Japanese Encephalitis | CDC [Internet]. 2019 [cited 2021 Dec 20]. : https://www.cdc.gov/japaneseen cephalitis/symptoms/index.html.

23. Solomon T, Ni H, Beasley DWC, et al. Origin and evolution of Japanese encephalitis virus in Southeast Asia. J Virol. 2003;77:3091-8.

24. WHO World Health Organization: Immunization, Vaccines and Biologicals. Vaccine preventable diseases Vaccines monitoring system 2020 Global Summary Reference Time Series: Japanese encephalitis [Internet]. [cited 2021 Sep 5]. https://apps.who.int/ immunization_monitoring/globalsummary/timeseries/tsincidenc ejapenc.html.

25. Huanyu W, Yixing L, Xiaofeng L, et al. Japanese Encephalitis in Mainland China. 7.

26. Feng Y, Fu S, Zhang H, et al. High incidence of Japanese encephalitis. Southern China Emerg Infect Dis. 2013;19:672-3.

27. Zheng Y, Li M, Wang H, et al. Japanese encephalitis and Japanese encephalitis virus in mainland China: JE and JEV in mainland China. Rev Med Virol. 2012;22:301-22.

28. Tiwari S, Singh RK, Tiwari R, et al. Japanese encephalitis: a review of the Indian perspective. Braz J Infect Dis. 2012;16:564-73.

29. Solomon T. Control of Japanese encephalitis-within our grasp? N Engl J Med. 2006;355:869-71.

30. Japanese Encephalities: National Center for Vector Borne Diseases Control (NCVBDC) [Internet] [cited 2021 Dec 20]. https:// nvbdcp.gov.in/index 1 .php?lang $=1 \&$ level $=1 \&$ sublinkid $=5773 \&$ lid=3693.

31. Win AYN, Wai KT, Harries AD, et al. The burden of Japanese encephalitis, the catch-up vaccination campaign, and health service providers' perceptions in Myanmar: 2012-2017. Trop Med Health. 2020;48:13.
32. Kumar Pant D, Tenzin T, Chand R, et al. Spatio-temporal epidemiology of Japanese encephalitis in Nepal, 2007-2015. PLoS ONE. 2017;12:e0180591.

33. Yen NT, Duffy MR, Hong NM, et al. Surveillance for Japanese encephalitis in Vietnam, 1998-2007. Am J Trop Med Hyg. 2010;83:816-9.

34. Li M-H, Fu S-H, Chen W-X, et al. Genotype V Japanese encephalitis virus is emerging. PLoS Negl Trop Dis. 2011;5:e1231.

35. Dutta K, Nazmi A, Basu A. Chemotherapy in Japanese encephalitis: are we there yet? Infect Disord Drug Targets. 2011;11:300-14.

36. Park K, Park K. Textbook of preventive medicine. 23rd ed. Jabalpur: Banarasidas Bhanot Publishers; 2005.

37. Paulke-Korinek M, Kollaritsch H. Japanese encephalitis and vaccines: past and future prospects. Wien Klin Wochenschr. 2008;120:15-9.

38. Japanese encephalitis [Internet]. [cited 2021 Sep 15]. https:// www.who.int/news-room/fact-sheets/detail/japanese-encephalit is.

39. Kumar R, Tripathi P, Baranwal M, et al. Randomized, controlled trial of oral ribavirin for Japanese encephalitis in children in Uttar Pradesh. India Clin Infect Dis. 2009;48:400-6.

40. Swarup V, Ghosh J, Ghosh S, et al. Antiviral and anti-inflammatory effects of rosmarinic acid in an experimental murine model of Japanese encephalitis. Antimicrob Agents Chemother. 2007;51:3367-70.

41. Dutta K, Ghosh D, Basu A. Curcumin protects neuronal cells from japanese encephalitis virus-mediated cell death and also inhibits infective viral particle formation by dysregulation of ubiquitin-proteasome system. J Neuroimmune Pharmacol. 2009;4:328-37.

42. Mishra MK, Ghosh D, Duseja R, et al. Antioxidant potential of minocycline in Japanese encephalitis virus infection in murine neuroblastoma cells: correlation with membrane fluidity and cell death. Neurochem Int. 2009;54:464-70.

43. Mishra MK, Dutta K, Saheb SK, et al. Understanding the molecular mechanism of blood-brain barrier damage in an experimental model of Japanese encephalitis: correlation with minocycline administration as a therapeutic agent. Neurochem Int. 2009;55:717-23.

44. Wu S-F, Lee C-J, Liao C-L, et al. Antiviral effects of an iminosugar derivative on flavivirus infections. J Virol. 2002;76:3596-604.

45. Appaiahgari MB, Vrati S. DNAzyme-mediated inhibition of Japanese encephalitis virus replication in mouse brain. Mol Ther. 2007;15:1593-9.

46. Wang S, Liu Y, Guo J, et al. Screening of FDA-approved drugs for inhibitors of japanese encephalitis virus infection. In Diamond MS, editor. J Virol [Internet]. 2017 [cited 2021 Dec 20];91. https://journals.asm.org/doi/10.1128/JVI.01055-17.

47. Solomon T, Dung NM, Wills B, et al. Interferon alfa-2a in Japanese encephalitis: a randomised double-blind placebo-controlled trial. The Lancet. 2003;361:821-6.

48. Dropulic B, Masters CL. Entry of neurotropic arboviruses into the central nervous system: an in vitro study using mouse brain endothelium. J Infect Dis. 1990;161:685-91.

49. Desai A, Shankar SK, Ravi V, et al. Japanese encephalitis virus antigen in the human brain and its topographic distribution. Acta Neuropathol. 1995. https://doi.org/10.1007/BF0030963.

50. Swarup V, Ghosh J, Mishra MK, et al. Novel strategy for treatment of Japanese encephalitis using arctigenin, a plant lignan. J Antimicrob Chemother. 2008;61:679-88.

51. Kurane I. Immune Responses to Japanese Encephalitis Virus. In: Mackenzie JS, Barrett ADT, Deubel V, editors. Jpn Enceph West Nile Viruses [Internet]. Berlin, Heidelberg: Springer Berlin 
Heidelberg; 2002 [cited 2021 Dec 20]. pp. 91-103. https://doi. org/10.1007/978-3-642-59403-8_5.

52. Cho JY, Kim AR, Yoo ES, et al. Immunomodulatory effect of arctigenin, a lignan compound, on tumour necrosis factor- $\alpha$ and nitric oxide production, and lymphocyte proliferation. J Pharm Pharmacol. 2010;51:1267-73.

53. Da Costa XJ, Brockman MA, Alicot E, et al. Humoral response to herpes simplex virus is complement-dependent. Proc Natl Acad Sci USA. 1999;96:12708-12.

54. Diamond MS, Shrestha B, Marri A, et al. B cells and antibody play critical roles in the immediate defense of disseminated infection by west nile encephalitis virus. J Virol. 2003;77:2578-86.

55. Clark R, Kupper T. Old meets new: the interaction between innate and adaptive immunity. J Invest Dermatol. 2005;125:629-37.

56. Mackenzie JS, Barrett ADT, Deubel V, editors. Japanese Encephalitis and West Nile Viruses [Internet]. Berlin, Heidelberg: Springer Berlin Heidelberg; 2002 [cited 2021 Dec 20]. https://doi.org/10.1007/978-3-642-59403-8.

57. Kesson AM, Blanden RV, Mullbacher A. The primary in vivo murine cytotoxic $\mathrm{T}$ cell response to the flavivirus. West Nile $\mathrm{J}$ Gen Virol. 1987;68:2001-6.

58. Kiermayr S, Kofler RM, Mandl CW, et al. Isolation of capsid protein dimers from the tick-borne encephalitis flavivirus and in vitro assembly of capsid-like particles. J Virol. 2004;78:8078-84.

59. Zakaria MK, Carletti T, Marcello A. Cellular targets for the treatment of flavivirus infections. Front Cell Infect Microbiol. 2018;8:398.

60. Wang S-H, Syu W-J, Huang K-J, et al. Intracellular localization and determination of a nuclear localization signal of the core protein of dengue virus. J Gen Virol. 2002;83:3093-102.

61. Poonsiri T, Wright GSA, Solomon T, et al. Crystal structure of the Japanese Encephalitis virus capsid protein. Viruses. 2019;11:623.

62. Sampath A, Padmanabhan R. Molecular targets for flavivirus drug discovery. Antiviral Res. 2009;81:6-15.

63. Perera R, Khaliq M, Kuhn RJ. Closing the door on flaviviruses: entry as a target for antiviral drug design. Antiviral Res. 2008;80:11-22.

64. Luca VC, AbiMansour J, Nelson CA, et al. Crystal structure of the Japanese encephalitis virus envelope protein. J Virol. 2012;86:2337-46.

65. Li L, Lok S-M, Yu I-M, et al. The flavivirus precursor membrane-envelope protein complex: structure and maturation. Science. 2008;319:1830-4.

66. Detection of a trypsin-like serine protease domain in flaviviruses and pestviruses-ScienceDirect [Internet]. [cited 2021 Dec 20]. https://www.sciencedirect.com/science/article/abs/ pii/0042682289906399.

67. Lescar J, Luo D, Xu T, et al. Towards the design of antiviral inhibitors against flaviviruses: the case for the multifunctional NS3 protein from Dengue virus as a target. Antiviral Res. 2008;80:94-101.

68. Liu X, Zhao X, Na R, et al. The structure differences of Japanese encephalitis virus SA14 and SA14-14-2 E proteins elucidate the virulence attenuation mechanism. Protein Cell. 2019;10:149-53.

69. Luo D, Vasudevan SG, Lescar J. The flavivirus NS2B-NS3 protease-helicase as a target for antiviral drug development. Antiviral Res. 2015;118:148-58.

70. Gorbalenya AE, Donchenko AP, Koonin EV, et al. N-terminal domains of putative helicases of flavi- and pestiviruses may be serine proteases. Nucleic Acids Res. 1989;17:3889-97.

71. Klema VJ, Ye M, Hindupur A, et al. Dengue virus nonstructural protein 5 (NS5) assembles into a dimer with a unique methyltransferase and polymerase interface. PLoS Pathog. 2016;12:e1005451.

72. Dong H, Zhang B, Shi P-Y. Flavivirus methyltransferase: a novel antiviral target. Antiviral Res. 2008;80:1-10.

73. Surana P, Satchidanandam V, Nair DT. RNA-dependent RNA polymerase of Japanese encephalitis virus binds the initiator nucleotide GTP to form a mechanistically important pre-initiation state. Nucleic Acids Res. 2014;42:2758-73.

74. Anantpadma M, Vrati S. siRNA-mediated suppression of Japanese encephalitis virus replication in cultured cells and mice. J Antimicrob Chemother. 2012;67:444-51.

75. Murakami M, Ota T, Nukuzuma S, et al. Inhibitory effect of RNAi on Japanese encephalitis virus replication in vitro and in vivo. Microbiol Immunol. 2005;49:1047-56.

76. Schneider WM, Chevillotte MD, Rice CM. Interferon-stimulated genes: a complex web of host defenses. Annu Rev Immunol. 2014;32:513-45.

77. Lin C-W, Wu C-F, Hsiao N-W, et al. Aloe-emodin is an interferon-inducing agent with antiviral activity against Japanese encephalitis virus and enterovirus 71. Int J Antimicrob Agents. 2008;32:355-9.

78. Sebastian L, Desai A, Yogeeswari P, et al. Combination of $\mathrm{N}$-methylisatin- $\beta$-thiosemicarbazone derivative (SCH16) with ribavirin and mycophenolic acid potentiates the antiviral activity of SCH16 against Japanese encephalitis virus in vitro. Lett Appl Microbiol. 2012;55:234-9.

79. Sebastian L, Desai A, Madhusudana SN, et al. Pentoxifylline inhibits replication of Japanese encephalitis virus: a comparative study with ribavirin. Int J Antimicrob Agents. 2009;33:168-73.

80. Takhampunya R, Ubol S, Houng H-S, et al. Inhibition of dengue virus replication by mycophenolic acid and ribavirin. J Gen Virol. 2006;87:1947-52.

81. Sehgal N, Kumawat KL, Basu A, et al. Fenofibrate reduces mortality and precludes neurological deficits in survivors in murine model of japanese encephalitis viral infection. PLoS ONE. 2012;7:5427.

82. Chen C-J, Raung S-L, Kuo M-D, et al. Suppression of Japanese encephalitis virus infection by non-steroidal anti-inflammatory drugs. J Gen Virol. 2002;83:1897-905.

83. P.N. Nair M. Current Scenario of Antiviral Drugs for Japanese Encephalitis. J Med Microbiol Diagn [Internet]. 2014 [cited 2021 Jun 1];03. https://www.omicsonline.org/open-access/currentscenario-of-antiviral-drugs-for-japanese-encephalitis-2161-0703. 1000133.php?aid $=25789$.

84. Shi Z, Wei J, Deng X, et al. Nitazoxanide inhibits the replication of Japanese encephalitis virus in cultured cells and in a mouse model. Virol J. 2014;11:10.

85. Rossignol J-F. Nitazoxanide: a first-in-class broad-spectrum antiviral agent. Antiviral Res. 2014;110:94-103.

86. Saxena SK, Mathur A, Srivastava RC. Inhibition of Japanese encephalitis virus infection by diethyldithiocarbamate is independent of its antioxidant potential. Antivir Chem Chemother. 2003;14:91-8.

87. Zhang Y, Wang Z, Chen H, et al. Antioxidants: potential antiviral agents for Japanese encephalitis virus infection. Int J Infect Dis. 2014;24:30-6.

88. Boldescu V, Behnam MAM, Vasilakis N, et al. Broad-spectrum agents for flaviviral infections: dengue, Zika and beyond. Nat Rev Drug Discov. 2017;16:565-86.

89. Mazzon M, Ortega-Prieto A, Imrie D, et al. Identification of broad-spectrum antiviral compounds by targeting viral entry. Viruses. 2019;11:176.

90. DrugVirus.info [Internet]. [cited 2021 Dec 21]. https://drugvirus. info/. 
91. Fan W, Qian S, Qian P, et al. Antiviral activity of luteolin against Japanese encephalitis virus. Virus Res. 2016;220:112-6.

92. Lu C-Y, Chang Y-C, Hua C-H, et al. Tubacin, an HDAC6 selective inhibitor, reduces the replication of the japanese encephalitis virus via the decrease of viral RNA synthesis. Int J Mol Sci. 2017;18:954.

93. Chang C-C, Ou Y-C, Raung S-L, et al. Antiviral effect of dehydroepiandrosterone on Japanese encephalitis virus infection. J Gen Virol. 2005;86:2513-23.

94. Yang J, Xu Y, Yan Y, et al. Small molecule inhibitor of ATPase activity of HSP70 as a broad-spectrum inhibitor against flavivirus infections. ACS Infect Dis. 2020;6:832-43.

95. Li Z, Sakamuru S, Huang R, et al. Erythrosin B is a potent and broad-spectrum orthosteric inhibitor of the flavivirus NS2B-NS3 protease. Antiviral Res. 2018;150:217-25.

96. Huang H-N, Rajanbabu V, Pan C-Y, et al. Modulation of the immune-related gene responses to protect mice against Japanese encephalitis virus using the antimicrobial peptide, tilapia hepcidin 1-5. Biomaterials. 2011;32:6804-14.

97. Kumar P, Lee SK, Shankar P, et al. A single siRNA suppresses fatal encephalitis induced by two different flaviviruses. PLoS Med. 2006;3:e96

98. Shen T, Liu K, Miao D, et al. Lentivirus-mediated RNA interference against Japanese encephalitis virus infection in vitro and in vivo. Antiviral Res. 2014;108:56-64.

99. Wu Z, Xue Y, Wang B, et al. Broad-spectrum antiviral activity of RNA interference against four genotypes of japanese encephalitis virus based on single MicroRNA polycistrons. PLoS ONE. 2011;6:e26304.

100. Shen T, Liu K, Miao D, et al. Effective inhibition of Japanese encephalitis virus replication by shRNAs targeting various viral genes in vitro and in vivo. Virology. 2014;454-455:48-59.

101. Yoo J-S, Kim C-M, Kim J-H, et al. Inhibition of Japanese encephalitis virus replication by peptide nucleic acids targeting cis-acting elements on the plus- and minus-strands of viral RNA. Antiviral Res. 2009;82:122-33.

102. Anantpadma M, Stein DA, Vrati S. Inhibition of Japanese encephalitis virus replication in cultured cells and mice by a peptide-conjugated morpholino oligomer. J Antimicrob Chemother. 2010;65:953-61.

103. Zhang N, Chen H-M, Koch V, et al. Ring-expanded ("Fat") nucleoside and nucleotide analogues exhibit potent in vitro activity against Flaviviridae NTPases/helicases, including those of the west Nile Virus, Hepatitis C Virus, and Japanese encephalitis virus. J Med Chem. 2003;46:4149-64.

104. Chen J, Yamada S, Hama Y, et al. Unique heparan sulfate from shrimp heads exhibits a strong inhibitory effect on infections by dengue virus and Japanese encephalitis virus. Biochem Biophys Res Commun. 2011;412:136-42.

105. Kim E, Okumura M, Sawa H, et al. Paradoxical effects of chondroitin sulfate-E on Japanese encephalitis viral infection. Biochem Biophys Res Commun. 2011;409:717-22.

106. Lee E, Pavy M, Young N, et al. Antiviral effect of the heparan sulfate mimetic, PI-88, against dengue and encephalitic flaviviruses. Antiviral Res. 2006;69:31-8.

107. Fan J, Liu Y, Xie X, et al. Inhibition of Japanese encephalitis virus infection by flavivirus recombinant e protein domain III. Virol Sin. 2013;28:152-60.

108. Zu X, Liu Y, Wang S, et al. Peptide inhibitor of Japanese encephalitis virus infection targeting envelope protein domain III. Antiviral Res. 2014;104:7-14.

109. Liang J-J, Wei J-C, Lee Y-L, et al. Surfactant-modified nanoclay exhibits an antiviral activity with high potency and broad spectrum. J Virol. 2014;88:4218-28.

110. Chang S-J, Chang Y-C, Lu K-Z, et al. Antiviral activity of Isatis indigotica extract and its derived indirubin against Japanese encephalitis virus. Evid-Based Complement Altern Med ECAM. 2012;2012:925830.

111. Chien Y-J, Chen W-J, Hsu W-L, et al. Bovine lactoferrin inhibits Japanese encephalitis virus by binding to heparan sulfate and receptor for low density lipoprotein. Virology. 2008;379:143-51.

112. Ishag HZA, Li C, Huang L, et al. Griffithsin inhibits Japanese encephalitis virus infection in vitro and in vivo. Arch Virol. 2013;158:349-58.

113. Lin R-J, Chien H-L, Lin S-Y, et al. MCPIP1 ribonuclease exhibits broad-spectrum antiviral effects through viral RNA binding and degradation. Nucleic Acids Res. 2013;41:3314-26.

114. Zhang T, Wu Z, Du J, et al. Anti- Japanese-encephalitis-viral effects of kaempferol and daidzin and their RNA-binding characteristics. PLoS ONE. 2012;7:e30259.

115. Sebastian L, Desai A, Shampur MN, et al. N-methylisatin-betathiosemicarbazone derivative (SCH 16) is an inhibitor of Japanese encephalitis virus infection in vitro and in vivo. Virol J. 2008;5:64.

116. Pambudi S, Kawashita N, Phanthanawiboon S, et al. A small compound targeting the interaction between nonstructural proteins $2 \mathrm{~B}$ and 3 inhibits dengue virus replication. Biochem Biophys Res Commun. 2013;440:393-8.

117. Borowski P, Heising MV, Miranda IB, et al. Viral NS3 helicase activity is inhibited by peptides reproducing the Arg-rich conserved motif of the enzyme (motif VI). Biochem Pharmacol. 2008;76:28-38.

118. Fang J, Sun L, Peng G, et al. Identification of three antiviral inhibitors against japanese encephalitis virus from library of pharmacologically active compounds 1280 . PLoS ONE. 2013;8:e78425.

119. Talarico L, Pujol C, Zibetti R, et al. The antiviral activity of sulfated polysaccharides against dengue virus is dependent on virus serotype and host cell. Antiviral Res. 2005;66:103-10.

120. Li Z, Brecher M, Deng Y-Q, et al. Existing drugs as broad-spectrum and potent inhibitors for Zika virus by targeting NS2B-NS3 interaction. Cell Res. 2017;27:1046-64.

121. Brecher M, Chen H, Li Z, et al. Identification and characterization of novel broad-spectrum inhibitors of the flavivirus methyltransferase. ACS Infect Dis. 2015;1:340-9.

122. Qiu X, Lei Y, Yang P, et al. Structural basis for neutralization of Japanese encephalitis virus by two potent therapeutic antibodies. Nat Microbiol. 2018;3:287-94.

123. Zhang Z-R, Zhang H-Q, Li X-D, et al. Generation and characterization of Japanese encephalitis virus expressing GFP reporter gene for high throughput drug screening. Antiviral Res. 2020;182:104884.

124. Kumar S, Maurya VK, Kabir R, et al. Antiviral activity of belladonna during Japanese encephalitis virus infection via inhibition of microglia activation and inflammation leading to neuronal cell survival. ACS Chem Neurosci. 2020;11:3683-96.

125. Ishag HZA, Li C, Huang $\mathrm{L}$, et al. Inhibition of Japanese encephalitis virus infection in vitro and in vivo by pokeweed antiviral protein. Virus Res. 2013;171:89-96.

126. Takegami T, Simamura E, Hirai K-I, et al. Inhibitory effect of furanonaphthoquinone derivatives on the replication of Japanese encephalitis virus. Antiviral Res. 1998;37:37-45.

127. Johari J, Kianmehr A, Mustafa MR, et al. Antiviral activity of baicalein and quercetin against the japanese encephalitis virus. Int J Mol Sci. 2012;13:16785-95.

128. Kim S-J, Park S-N, Oh J-W. Antiviral effect of amphotericin B on japanese encephalitis virus replication. 8.

129. Mastrangelo E, Pezzullo M, De Burghgraeve T, et al. Ivermectin is a potent inhibitor of flavivirus replication specifically targeting NS3 helicase activity: new prospects for an old drug. J Antimicrob Chemother. 2012;67:1884-94. 
130. Seniya C, Mishra H, Yadav A, et al. Antiviral potential of 4-hydroxypanduratin A, secondary metabolite of Fingerroot, Boesenbergia pandurata (Schult.), towards Japanese Encephalitis virus NS2B/NS3 protease. Bioinformation. 2013;9:54-60.

131. Lv B-M, Tong X-Y, Quan Y, et al. Drug repurposing for Japanese encephalitis virus infection by systems biology methods. Molecules. 2018;23:3346.

132. Gupta SK, Singh S, Nischal A, et al. Molecular docking and simulation studies towards exploring antiviral compounds against envelope protein of Japanese encephalitis virus. Netw Model Anal Health Inform Bioinforma. 2013;2:231-43.

133. Lundin KE, Good L, Strömberg R, et al. Biological Activity and Biotechnological Aspects of Peptide Nucleic Acid. Adv Genet [Internet]. 2006 [cited 2021 Dec 21]. pp. 1-51. https://linki nghub.elsevier.com/retrieve/pii/S0065266006560018.

134. Falgout B, Markoff L. Evidence that flavivirus NS1-NS2A cleavage is mediated by a membrane-bound host protease in the endoplasmic reticulum. J Virol. 1995;69:7232-43.

135. Yamashita T, Unno H, Mori Y, et al. Crystal structure of the catalytic domain of Japanese encephalitis virus NS3 helicase/ nucleoside triphosphatase at a resolution of $1.8 \AA$. Virology. 2008;373:426-36.

136. Lu G, Gong P. Crystal structure of the full-length japanese encephalitis virus NS5 reveals a conserved methyltransferasepolymerase interface. PLoS Pathog. 2013;9:e1003549.

137. Weinert $T$, Olieric V, Waltersperger $S$, et al. Fast native-SAD phasing for routine macromolecular structure determination. Nat Methods. 2015;12:131-3.

138. Baharuddin A, Hassan A, Sheng G, et al. Current approaches in antiviral drug discovery against the flaviviridae family. Curr Pharm Des. 2014;20:3428-44.

139. Bhat SM, Mudgal PP, Sudheesh N, et al. Spectrum of candidate molecules against Chikungunya virus - an insight into the antiviral screening platforms. Expert Rev Anti Infect Ther. 2019;17:243-64

140. Disha KS, Puranik R, Sudheesh N, et al. Structure-based identification of small molecules against influenza A virus endonuclease: an in silico and in vitro approach. Pathog Dis. 2020;78:032.

141. Sharma G. Chapter-5 Molecular docking studies-synthesis and biological screening of certain quinonoids [Internet]. Department of Chemistry, Karunya University; 2013. http:// hdl.handle.net/10603/23480.

142. Fang J, Li H, Kong D, et al. Structure-based discovery of two antiviral inhibitors targeting the NS3 helicase of Japanese encephalitis virus. Sci Rep. 2016;6:34550.

143. Rath M, Sahu DMC, Sahu DSK. Docking and Inhibition of Antiviral Ligands of Japanese Encephalitis Virus with Capsid Envelope Strain SA-14-14-2(3P54). 2016; 7:4.

144. Natesh J, Mondal P, Penta D, et al. Culinary spice bioactives as potential therapeutics against SARS-CoV-2: computational investigation. Comput Biol Med. 2021;128:104102.

145. UCSF Chimera Home Page [Internet]. [cited 2021 Sep 6]. https://www.rbvi.ucsf.edu/chimera/.

146. Dwivedi VD, Singh A, El-Kafraway SA, et al. Mechanistic insights into the Japanese Encephalitis Virus RNA dependent RNA polymerase protein inhibition by bioflavonoids from Azadirachta indica [Internet]. Bioinformatics; 2021 [cited 2021 Sep 6]. http://biorxiv.org/lookup/doi/10.1101/2021.05. 31.446388.

147. Navyashree V, Kant K, Kumar A. Natural chemical entities from Arisaema genus might be a promising break-through against Japanese encephalitis virus infection: a molecular docking and dynamics approach. J Biomol Struct Dyn. 2021;39:1404-16.
148. Nath M, Deb B. A computational approach of antibiotics as novel drug target for Japanese encephalitis virus NS helicase/ nucleoside triphosphatase. MOJ Proteomics Bioinforma [Internet]. 2018 [cited 2021 Sep 6];7. https://medcraveonline.com/ $\mathrm{MOJPB} / \mathrm{a}$-computational-approach-of-antibiotics-as-noveldrug-target-for-japanese-encephalitis-virus-ns-helicasenucleos ide-triphosphatase.html.

149. Szymański P, Markowicz M, Mikiciuk-Olasik E. Adaptation of high-throughput screening in drug discovery-toxicological screening tests. Int J Mol Sci. 2011;13:427-52.

150. Rothan HA, Yusof R. Antiviral and VIRU6: 7CIDAL activities of sulphated polysaccharides against Japanese encephalitis virus. Trop Biomed. 2020. https://doi.org/10.47665/tb.37.3. 713.

151. Atasoy T, Bostanabad Y. Western Blot: an alternative to the plaque reduction assay for in vitro determination of HSV susceptibility to acyclovir. 1.

152. Roehrig JT, Hombach J, Barrett ADT. Guidelines for plaquereduction neutralization testing of human antibodies to dengue viruses. Viral Immunol. 2008;21:123-32.

153. Plaque Reduction Assay [Internet]. [cited 2021 Dec 21]. https://isirv.org/site/index.php/methodology/plaque-reduc tion-assay.

154. Li C, Ge L, Yu Y, et al. A tripeptide (NSK) inhibits Japanese encephalitis virus infection in vitro and in vivo. Arch Virol. 2014;159:1045-55.

155. Dhanasekaran S, Doherty TM, Kenneth J. Comparison of different standards for real-time PCR-based absolute quantification. J Immunol Methods. 2010;354:34-9.

156. Bar T, Kubista M, Tichopad A. Validation of kinetics similarity in qPCR. Nucleic Acids Res. 2012;40:1395-406.

157. Stránská R, van Loon AM, Polman M, et al. Application of real-time PCR for determination of antiviral drug susceptibility of herpes simplex virus. Antimicrob Agents Chemother. 2002;46:2943-7.

158. Flint J. Principles of virology. 4th ed. Washington DC: American Society of Microbiology; 2015.

159. Kovanich D, Saisawang C, Sittipaisankul P, et al. Analysis of the Zika and Japanese encephalitis virus NS5 interactomes. J Proteome Res. 2019;18:3203-18.

160. Alvarez A, Barisone GA, Diaz E. Focus formation: a cell-based assay to determine the oncogenic potential of a gene. J Vis Exp JoVE. 2014;2014:51742.

161. Tani H, Shiokawa M, Kaname Y, et al. Involvement of ceramide in the propagation of Japanese encephalitis virus. J Virol. 2010;84:2798-807.

162. Guo J, Jia X, Liu Y, et al. Screening of Natural Extracts for Inhibitors against Japanese Encephalitis Virus Infection. Antimicrob Agents Chemother [Internet]. 2020 [cited 2021 Dec 18];64. https://journals.asm.org/doi/10.1128/AAC.02373-19.

163. Tokunaga M, Miyamoto Y, Suzuki T, et al. Novel anti-flavivirus drugs targeting the nucleolar distribution of core protein. Virology. 2020;541:41-51.

164. Proteomics C. Co-immunoprecipitation (Co-IP) [Internet]. Creat. Proteomics. [cited 2021 Dec 21]. https://www.creative-prote omics.com/services/co-immunoprecipitation-co-ip.htm.

165. Prichard MN, Turk SR, Coleman LA, et al. A microtiter virus yield reduction assay for the evaluation of antiviral compounds against human cytomegalovirus and herpes simplex virus. J Virol Methods. 1990;28:101-6.

166. Lien J-C, Wang C-Y, Lai H, et al. Structure analysis and antiviral activity of CW-33 analogues against Japanese encephalitis virus. Sci Rep. 2018;8:16595. 
167. Sebastian L, Madhusudana SN, Ravi V, et al. Mycophenolic acid inhibits replication of Japanese encephalitis virus. Chemotherapy. 2011;57:56-61.

168. Clark DC, Brault AC, Hunsperger E. The contribution of rodent models to the pathological assessment of flaviviral infections of the central nervous system. Arch Virol. 2012;157:1423-40.

169. Tripathi A, Banerjee A, Vrati S. Development and characterization of an animal model of Japanese encephalitis virus infection in adolescent C57BL/6 mouse. Dis Model Mech. 2021;14:dmm049176.

170. Product development under the animal rule guidance for industry. 2015;54.

171. Li Y, Ye J, Yang X, et al. Infection of mouse bone marrowderived dendritic cells by live attenuated Japanese encephalitis virus induces cells maturation and triggers $\mathrm{T}$ cells activation. Vaccine. 2011;29:855-62.

172. Hase T, Dubois DR, Summers PL. Comparative study of mouse brains infected with Japanese encephalitis virus by intracerebral or intraperitoneal inoculation. Int J Exp Pathol. 1990;71:857-69.

173. Greenlee JE. Effect of host age on experimental K virus infection in mice. Infect Immun. 1981;33:297-303.

174. Hu X-T, Li Q-F, Ma C, et al. Reduction patterns of Japanese encephalitis incidence following vaccine introduction into longterm expanded program on immunization in Yunnan Province. China Infect Dis Poverty. 2019;8:102.

175. Hurt CR, Lingappa VR, J. Hansen W. The Emergence of SmallMolecule Inhibitors of Capsid Assembly as Potential Antiviral Therapeutics. Annu Rep Med Chem [Internet]. Elsevier; 2011 [cited 2021 Dec 30]. p. 283-297. https://linkinghub.elsevier.com/ retrieve/pii/B9780123860095000102.

176. Michaelis M, Kleinschmidt MC, Doerr HW, et al. Minocycline inhibits West Nile virus replication and apoptosis in human neuronal cells. J Antimicrob Chemother. 2007;60:981-6.

177. Lu C-T, Zhao Y-Z, Wong HL, et al. Current approaches to enhance CNS delivery of drugs across the brain barriers. Int J Nanomedicine. 2014;9:2241-57.

178. Engelhardt B, Sorokin L. The blood-brain and the blood-cerebrospinal fluid barriers: function and dysfunction. Semin Immunopathol. 2009;31:497-511.

179. Ye J, Jiang R, Cui M, et al. Etanercept reduces neuroinflammation and lethality in mouse model of Japanese encephalitis. J Infect Dis. 2014;210:875-89.

180. Mishra MK, Basu A. Minocycline neuroprotects, reduces microglial activation, inhibits caspase 3 induction, and viral replication following Japanese encephalitis. J Neurochem. 2008;105:1582-95.

181. Kimura-Kuroda J, Yasui K. Protection of mice against Japanese encephalitis virus by passive administration with monoclonal antibodies. J Immunol Baltim Md. 1950;1988(141):3606-10.

182. Zou G, Xu HY, Qing M, et al. Development and characterization of a stable luciferase dengue virus for high-throughput screening. Antiviral Res. 2011;91:11-9.

183. Schoggins JW, Dorner M, Feulner M, et al. Dengue reporter viruses reveal viral dynamics in interferon receptor-deficient mice and sensitivity to interferon effectors in vitro. Proc Natl Acad Sci. 2012;109:14610-5.

\section{Authors and Affiliations}

\section{Shaun Joe ${ }^{1} \cdot$ Abdul Ajees Abdul Salam $^{2} \cdot$ Ujjwal Neogi $^{1,3} \cdot$ Naren Babu N $^{1} \cdot$ Piya Paul Mudgal $^{1}$ (C)}

Piya Paul Mudgal

piya.mudgal@manipal.edu

1 Manipal Institute of Virology, Manipal Academy of Higher Education, Manipal, Karnataka 576104, India

2 Department of Atomic and Molecular Physics, Centre for Applied Nano Sciences, Manipal Academy of Higher Education, Manipal, Karnataka 576104, India
Division of Clinical Microbiology, Department of Laboratory Medicine, Karolinska Institute, ANA Futura, Stockholm, Sweden 